\title{
An Examination of Wake Effects and Power Production for a Group of Large Wind Turbines
}

D. L. Elliott

J. W. Buck

J. C. Barnard

April 1988

Prepared for the U.S. Department of Energy under Contract DE-AC06-76RLO 1830

Pacific Northwest Laboratory

Operated for the U.S. Department of Energy by Battelle Memorial Institute 


\title{
DISCLAIMER
}

This report was prepared as an account of work sponsored by an agency of the United States Government. Neither the United States Government nor any agency thereof, nor Battelle Mernorial Institute, nor any or their employees, makes any warranty, expressed or implied, or assumes any legal liability or responsibility for the accuracy, completeness, or usefulness of any information, apparatus, product, or process disciosed, or represents that its use would not infringe privately owned rights. Reference herein to any specific commercial product, process, or service by trade name, trademark, manufacturer, or otherwise does not necessarily constitute or imply its endorsement, recommendation, or favoring by the United States Government or any agency thereof, or Battelle Memorial Institute. The views and opinions of authors expressed herein do not necessarily state or reflect those of the United States Government or any agency thereof, or Battelle Memorial Institute.

\author{
PACIFIC NORTHWEST LABORATORY \\ operated by \\ BATTELLE MEMORIAL INSTITUTE \\ for the \\ UNITED STATES DEPARTMENT OF ENERGY \\ under Contract DE-AC06-76RLO 1830
}

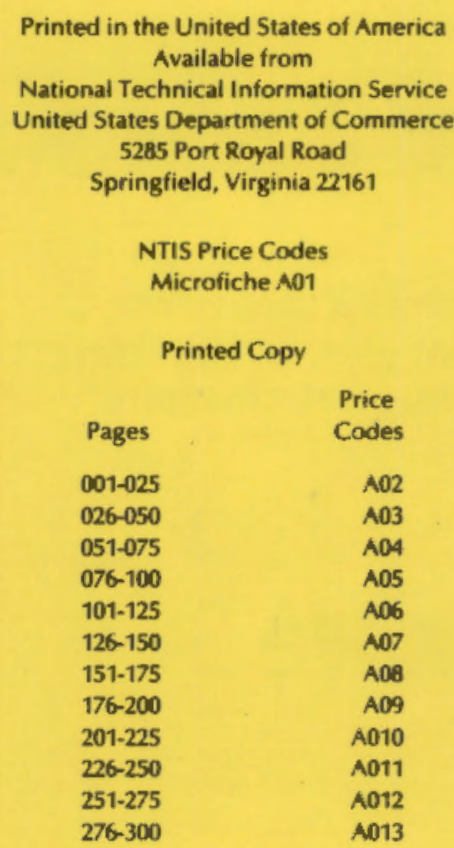


AN EXAMINATION OF WAKE EFFECTS AND POWER PRODUCTION FOR A GROUP OF LARGE WIND TURBINES

D. L. Elliott

J. W. Buck

J. C. Barnard

April 1988

Prepared for the U.S. Department of Energy under Contract DE-AC06-76RLO 1830

Pacific Northwest Laboratory

Richland, Washington 99352 


\section{SUMMARY}

Data from a group of three MOD-2 wind turbines and two meteorological towers at Goodnoe Hills were analyzed to evaluate turbine power output and wake effects (losses in power production due to operation of upwind turbines), and atmospheric factors influencing them. The influences of variations in the ambient wind speed, wind direction, and turbulence intensity were the primary factors evaluated. Meteorological and turbine data collected at the Goodnoe Hills site from April 1 to October 17, 1985, were examined to select the data sets for these analyses. The data were 1-min averages of 1-s values.

Wind data from the two meteorological towers were evaluated to estimate the effect of a wake from an upwind turbine on the wind flow measured at the downwind tower. Maximum velocity deficits were about $25 \%$ and $12 \%$ at downwind distances of 5.8 and 8.3 rotor diameters (D), respectively. However, the maximum deficits at $5.8 \mathrm{D}$ were about $14^{\circ}$ off the centerline orientation between the turbine and the tower, indicating significant wake curvature. This wake curvature was also evident for the $8.3 \mathrm{D}$ wake case. Velocity deficits were found to depend on the ambient wind speed, ranging from $27^{\circ}$ at lower speeds (15 to $25 \mathrm{mph}$ ) to $20 \%$ at higher speeds ( 30 to $35 \mathrm{mph}$ ). Turbulence intensity increases dramatically in the wake by factors of about 2.3 and 1.5 over ambient conditions at $5.8 \mathrm{D}$ and $8.3 \mathrm{D}$, respectively.

An analysis of the ambient (non-wake) power production for all three turbines showed that the MOD-2 power output depends, not only on wind speed, but also on the turbulence intensity. At wind speeds below rated, there was a dramatic difference in turbine power output between low and high turbulence intensities for the same wind speed. One of the turbines had vortex generators on the blades. This turbine produced from $10 \%$ to $13 \%$ more power than the other two turbines when speeds were from 24 to $31 \mathrm{mph}$.

An analysis of the average power deficits at $6.7 \mathrm{D}$ found that power deficits depend on both the ambient wind speed and turbulence intensity. Power deficits are greatest at low wind speeds and low turbulence intensities and decrease with increasing wind speed and/or turbulence intensity. Maximum average power deficits at $20 \mathrm{mph}, 25 \mathrm{mph}$, and $30 \mathrm{mph}$ are $43 \%, 28 \%$, and $10 \%$, respectively, for low turbulence intensity and $32 \%, 17 \%$, and $9 \%$, respectively, 
for all turbulence intensities. As with the velocity deficits, the maximum power deficits were substantially off (by $10^{\circ}$ to $12^{\circ}$ ) the centerline orientation between the upwind and downwind turbines, indicating a significant wake curvature. 


\section{ACKNOWLEDGMENTS}

The wind turbine construction, operation, and studies at the Goodnoe Hills site were a cooperative effort between the Bonneville Power Administration (BPA), the U.S. Department of Energy (DOE), Boeing Aerospace Corporation (BAC). the National Aeronautics and Space Administration (NASA)/Lewis Research Center, and Oregon State University (OSU). We would like to thank several individuals of the many who contributed significant assistance to the Pacifici Northwest Laboratory's (PNL's) meteorological and wake studies over the years.

At PNL, Dave Renne and Bill Sandusky began these studies and directed their course. Jim Schroeder and Ron Gilbert were responsible for the data system and support equipment. Bernie Holst, Owen Abbey, and Gary Dennis were invaluable in maintaining equipment onsite and keeping the PNL tower operational. Shirley Bradymire did most of the data processing over the years. Al Miller and Don Hadley were very helpful in interpreting the results from the data. Gene Gower assisted in producing the computer-generated plots for this report.

At the Goodnoe Hills site, Virgil Kirkendahl of NASA, Jack Betty of BAC, and Roger Bennet and Ron Holeman of BPA provided assistance and advice whenever necessary and their cooperation contributed to the success of the studies. Bob Baker of OSU also contributed important efforts and advice.

We are grateful to these and the many other individuals whose talents and energy were directed toward successful collection and analys is of the Goodnoe Hills data. 


+




\section{CONTENTS}

SUMMARY ......................... $i$ i ACKNOWLEDGMENTS ....................

1.0 INTRODUCTION . . . . . . . . . . . . . . . . 1.1

2.0 GOODNOE HILLS DATA COLLECTION PROGRAM . . . . . . . . 2.1

2.1 DESCRIPTION OF DATA COLLECTED IN 1985

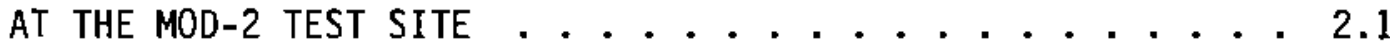

2.2 DATA SETS USED FOR THE ANALYSIS ........... 2.3

3.0 DATA ANALYSIS AND RESULTS . . . . . . . . . . . 3.1

3.1 ANALYSIS OF WAKE VELOCITY DEFICITS AND TURBULENCE

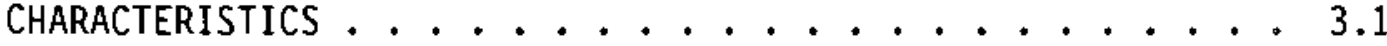

3.2 NON-WAKE POWER CURVES FOR THE MOD-2S AT GOODNOE HILLS . . . 3.10

3.3 ANALYSIS OF WAKE POWER DEFICITS AND THEIR VARIATION AS A FUNCTION OF WIND SPEED, WIND DIRECTION, AND

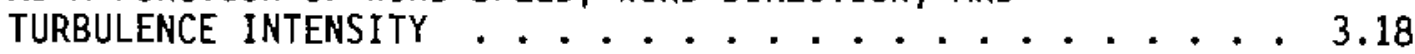

3.4 COMPARISON OF POWER DEFICITS TO WAKE MODEL

ESTIMATES . . . . . . . . . . . . 3.26

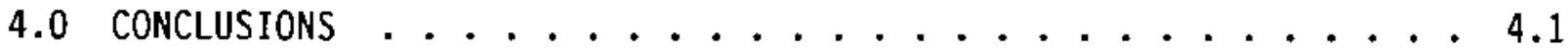

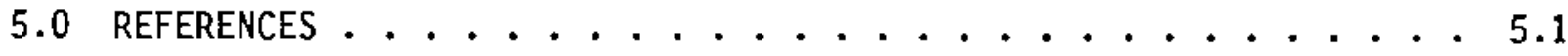
APPENDIX A - DESCRIPTION OF THE DISTRIBUTED DATA SYSTEM (DDS) . . . . A.1 APPENDIX B - DATA PROCESSING ............... B.1 


\section{FIGURES}

2.1 Relative Position of the Three MOD-2 Wind Turbines and Two Meteorological Towers at the Goodnoe Hills

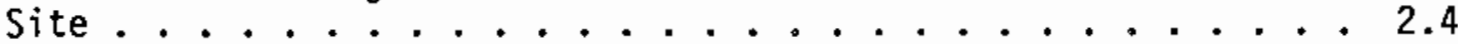

2.2 Incident Wind Directions Necessary for Centerline Wake Conditions and Distances Between Structures for All Combinations of Turbines and Towers .......... 2.4

3.1 Non-Wake and Wake Wind Direction Frequency Distributions . . . 3.3

3.2 Non-Wake and Wake Wind Speed Frequency Distributions . . . . 3.4

3.3 Non-Wake and Wake Turbulence Intensity Frequency

Distributions. ................... 3.6

3.4 The Ambient (Non-Wake) and Wake Wind Speed Ratio Plotted Versus the BPA Wind Direction. . . . . . . . 3.7

3.5 The PNL/BPA Wind Speed Ratio Plotted Versus BPA Wind Direction and Segregated With Respect to BPA wind Speed for the Turbine \#2/PNL Wake Case. . . . . . 3.8

3.6 The Ambient (Non-Wake) and Wake Turbulence Intensity Ratio Plotted Versus the BPA Wind Direction. ....... 3.9

3.7 Frequency Distribution of Power Data When the Wind Turbines Were $\underline{0 \text { ff }}$ for Turbines $\# 1, \# 2$, and \#3 ....... 3.11

3.8 Time Series Plots of the Daily Average Zero Power offsets for Turbines \#1,\#2, and \#3 .......... 3.12

3.9 Non-Wake Power Curves, as a Function of BPA 195- $\mathrm{ft}$ Wind Speed for Turbines \#1,\#2, and \#3.......... 3.14

3.10 Comparison of the Non-Wake Power Output for Turbines \#1,

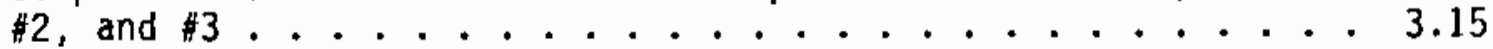

3.11 Difference in Power Output (Non-Wake) for Turbines \#1,

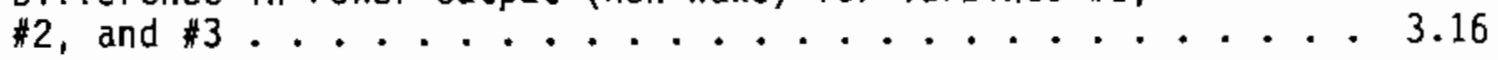

3.12 Non-Wake Power Output as a Function of Wind Speed and Turbulence Intensity for Turbines $\# 1, \# 2$, and $\# 3 \ldots . . .3 .17$

3.13 Average Power Deficits for Turbine \#1 Downwind of Turbine \#2 as a Function of BPA 195-ft Wind Speed

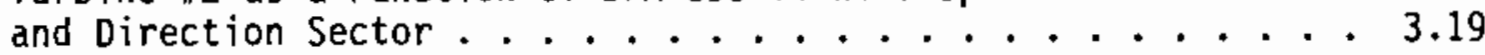


3.14 Average Power Deficits for Turbine \#1 Downwind of Turbine \#2 as a Function of BPA 195-ft Wind Speed

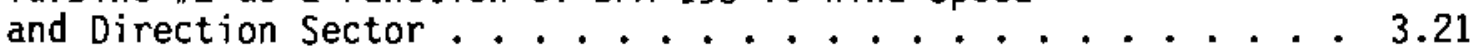

3.15 Composite Cross-Wake Profile of Average Power Deficits for Turbine \#1 Downwind of Turbine \#2. . . . . . . . . . 3.22

3.16 Average Power Deficits as a Function of Ambient Turbulence Intensity and Wind Speed for Turbine \#1 Downwind of Turbine \#2 for the Wind Direction Sector $281^{\circ}-291^{\circ}$. . . . . . . . . . . . . . 3.23

3.17 Average Power Deficits as a Function of Ambient Turbulence Intensity and Wind Speed for Turbine \#1 Downwind of Turbine 2 for the Wind Direction

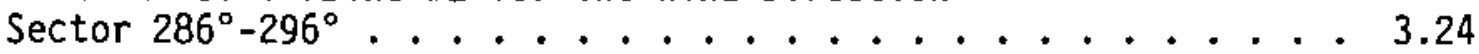

3.18 Wake Power Curves for Turbine \#1 Downwind of Turbine \#2 for the Wind Direction Sector $281^{\circ}-291^{\circ}$. . . . . . . . 3.25

3.19 Comparison of the Longitudinal Turbulence Intensities and Transverse Turbulence Intensities at Goodnoe Hills, Based on 1985 Data from the 195-ft Level of the BPA Meteorological Tower for Wind Speeds $>13 \mathrm{mph}$ and Wind Directions Between $220^{\circ}$ and $320^{\circ}$. . . . . . . . . . . 3.27 


\section{$\underline{\text { TABLES }}$}

2.1 Data Channels Collected on DDS During Period April 1

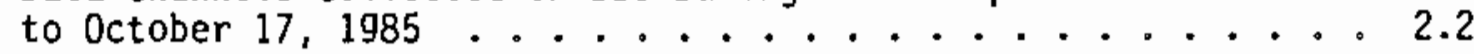

2.2 Data Channels Chosen for Analys is During Period

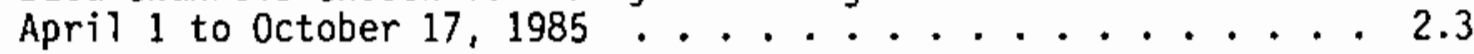

3.1 Number of 1-min-Averaged Samples of Power Data for the Wind Direction Sectors in Figure 3.13 . . . . . . 3.19

3.2 Number of 1-min-Averaged Samples of Power Data for the Wind Direction Sectors in Figure 3.14 . . . . . 3.21

3.3 Number of 1-min-Averaged Samples of Power Data in Wind Direction Sector $281^{\circ}-291^{\circ}$ for the Turbulence Intensity Categories in Figure $3.16 \ldots \ldots . \ldots 3.23$

3.4 Number of 1-min-Averaged Samples of Power Data in Wind Direction Sector $286^{\circ}-296^{\circ}$ for the Turbulence Intensity Categories in Figure $3.17 \ldots \ldots .25$

3.5 Percent Power Deficits for Turbine \#1 Downwind of Turbine \#2 Calculated from the Modified Lissaman Model Versus the Measured Results for Wind Directions $281^{\circ}-291^{\circ}$, as a Function of BPA 195-ft Wind Speed and Turbulence Intensity 


\subsection{INTRODUCTION}

In the fall of 1979, the U.S. Department of Energy (DOE) selected the Goodnoe Hills site, proposed by the Bonneville Power Administration (BPA), for the installation of a cluster of three MOD-2 wind turbine generator systems. Each MOD-2 is rated at $2500 \mathrm{kH}$. This site, selected from 20 candidate sites proposed by utility systems around the United States, provided a unique combination of high annual average wind speeds, site accessibility, strong utility support, high public visibility, and significant opportunity for performing a variety of tests on the first cluster of large turbines ever to be installed.

The Goodnoe Hills site, which is located in Washington State near $45^{\circ} 47.1^{\prime} \mathrm{N}$ and $120^{\circ} 33.4^{\prime} \mathrm{W}$, is approximately 20 miles east of the town of Goldendale, Washington, and approximately $120 \mathrm{miles}$ east of Portland, Oregon. The site is on top of a ridge, oriented approximately east-west, at an elevation of $2600 \mathrm{ft}$ about 3 miles north of the Columbia River. The terrain is relatively flat at the top of the ridge, although numerous gullies cut across the site; the gullies become quite deep on both the north and south sides. The ridge drops quite steeply to the river on the south side and more gradually to the Goldendale valley on the north side. Vegetation at the site consists almost entirely of low sagebrush and grass, with scrub oak found in the deeper gullies to the north and western edges of the site.

The MOD-2 wind turbine is a two-blade, teetering-hub, upwind machine. The rotor, which is $300 \mathrm{ft}$ in diameter and weighs 50 tons, is attached to a nacelle housing the gearbox and a 2500-kW generator, and sits atop a cylindrical 200-ft high tower. Rotor speed control is accomplished by pitch control of the outer $45 \mathrm{ft}$ of each blade. The machines were designed and manufactured by the Boeing Aerospace Corporation (BAC) for the DOE's Federal Wind Energy Program. The large machine development activities of the Wind Energy Program were managed by the National Aeronautics and Space Administration (NASA)/Lewis Research Center for the DOE.

Immediately following the selection of the site, a multi-agency test board was created to design and manage the experimental phase of the MOD-2 research 
program. This test board consisted of representatives from NASA/Lewis, BPA, BAC, Pacific Northwest Laboratory (PNL), and the Solar Energy Research Institute (SERI).

The initial actions of this test board were to establish the precise configuration of the cluster at the site and to design a data system that would support the MOD-2 research program. A triangular array was determined to be the most suitable configuration, since it would provide the best opportunity to measure the effect of the wake of an upwind machine on the power output of a downwind machine. This information was considered to be critical for future commercial wind farm activities and was a key objective of the MOD-2 test program. This triangular array would provide opportunities of monitoring wake effects at spacings of approximately 5, 7, and 10 rotor diameters (D). The data system chosen by the test board consisted of a central data logging facility that monitored signals from a variety of parameters at the three wind turbines. Simultaneously, this system monitored wind speed and direction information and other meteorological parameters collected at various levels on two meteorological towers installed at the site: a 200-ft tower operated by BPA and a 350-ft tower operated by PNL.

The main objective of this report is to analyze the meteorological and turbine data collected at the Goodnoe Hills site from April 1 to October 17, 1985, for the purpose of evaluating turbine power output and wake effects and their variability as a function of wind speed, wind direction, and turbulence intensity. Previous studies on the wind characteristics, wakes, and turbine power production have been performed for the Goodnoe Hills site using data sets collected prior to 1985 . These included PNL studies reported by Buck and Renne (1985), Miller, Wegley, and Buck (1984), Liu et al. (1983), Lissaman, Zambrano, and Gyatt (1983), and Hadley and Renne (1983), and other studies (e.g., for BAC, BPA, NASA/Lewis) such as those of Baker and Walker (1982, 1985), Miller (1985), Germain (1984), and Sullivan (1984). Most of the studies focused primarily on wake characteristics and velocity and power deficits induced by the upwind turbine wakes. A variety of techniques and measurements were used in previous studies to estimate wake characteristics. These included turbine as well as tower parameters, measurements using kites and tethered balloons, and flow visualization. Phenomena that can affect the results of 
wake measurements, such as flow variability across the site and differences in machine operating conditions, were discussed and quantitatively treated in some of the previous studies.

The 1985 data set, upon which this report is based, contains considerably more turbine and tower data for use in analyzing turbine power production and wake effects than previous data sets collected at the Goodnoe Hills site, such as the 1982 data set which has been analyzed and reported by Buck and Renne (1985), Germain (1984), Hadley and Renne (1983), and others. Because of problems with the turbines, the amount of wake data collected in 1982 was quite limited. In 1985, all three turbines were operational and much more data were collected for considerably longer periods of time than in 1982. Another shortcoming of the 1982 data set is that only limited meteorological conditions are represented in the September to November data collection period; no data were available for the windiest periods at the site, which usually occur in the spring and summer months. The 1985 data set contains almost seven months of turbine and tower data, mostly from the spring and summer months, which are usually the best power-producing months. 
. 


\subsection{GOOONOE HILLS DATA COLLECTION PROGRAM}

\subsection{DESCRIPTION OF DATA COLLECTED IN 1985 AT THE MOD-2 TEST SITE}

A variety of instrumentation has been installed on the three MOD-2 turbines and two meteorologica] towers to measure turbine, wind and other meteorological parameters at Goodnoe Hills. In 1985, the signals received from each turbine were generator field current, utility power, generator power, energized voltage, rotor speed, yaw error, \#1 blade pitch angle, and nacelle position. The 350-ft PNL meteorological tower had wind speed and direction sensors at 50-, 125-, 200-, 275-, and 350-ft levels. These levels gave wind information for the upper and lower limits of the rotor and its hub as wel1 as two points halfway down the blade length.

The type of wind sensor installed at each level on the PNL tower was the Climatronics $^{\mathbf{T}} \mathbf{4 6 0}$ Model, which consists of anemometer cups and a directional vane. The distance constants for this wind measuring system are reported to be $5 \mathrm{ft}$ (maximum) for wind speed and $3.7 \mathrm{ft}$ for wind direction. Other sensors at the PNL tower were an air temperature sensor at $33 \mathrm{ft}$, delta temperature sensor for the difference between 350- and 33-ft levels, and an atmospheric pressure sensor at $200 \mathrm{ft}$.

The 200-ft meteorological tower maintained by BPA had wind speed and direction sensors at 50- and 195-ft levels, an air temperature sensor at $50 \mathrm{ft}$, and an atmospheric pressure sensor near ground level. The type of wind sensors installed on the BPA tower was the Belfort ${ }^{T \mathrm{~T}}$ Aerovane Model 120 HD Type L, which is a three-blade propeller installed on the front of the directional vane. The distance constants for this wind measuring system are reported to be $15 \mathrm{ft}$ for wind speed and $34 \mathrm{ft}$ for wind direction.

Calibration of the sensors and electronics of the systems was done routinely on all equipment, including the turbines, although the turbine sensor calibrations presented some problems with zero drift, which are discussed in more detail in Section 3.2 of this report.

\footnotetext{
${ }^{T} \mathrm{C}$ Climatronics, 626 Sonora Ave., Glendale, CA 91201.

Tuelfort Instrument Co., 2620 Concord Ave., \#102, Alhambra, CA 91803.
} 
A centralized data logging system, known as the Distributed Data System (DDS), was installed at the site to monitor data collected from both the meteorological towers and selected data from the three MOD-2 turbines. The specifics of the DDS are described in Appendix A.

This report is based on data collected from April 1, 1985, to October 17, 1985. Table 2.1 lists the parameters that were collected by the DDS during the 1985 period.

TABLE 2.1. Data Channels Collected on DDS During Period April 1 to October 17, 1985

PHL TOWER:

1) Wind direction $125 \mathrm{ft}$

2) Wind direction $50 \mathrm{ft}$

3) Wind direction $200 \mathrm{ft}$

4) Wind direction $350 \mathrm{ft}$

5) Wind speed $125 \mathrm{ft}$

6) Wind speed $50 \mathrm{ft}$

7) Wind speed $200 \mathrm{ft}$

8) Wind speed $350 \mathrm{ft}$

9) Air temperature $33 \mathrm{ft}$

10) Air temperature difference between $350 \mathrm{ft}$ and $33 \mathrm{ft}$

11) Air flow (temperature aspirator) $33 \mathrm{ft}$

12) Air flow (temperature aspirator) $350 \mathrm{ft}$

13) Atmospheric pressure $200 \mathrm{ft}$

14) Wind direction $275 \mathrm{ft}$

15) Hind speed $275 \mathrm{ft}$

\section{BPA TOWER:}

1) Wind speed $50 \mathrm{ft}$

2) Wind direction $50 \mathrm{ft}$

3) Wind speed $195 \mathrm{ft}$

4) Wind direction $195 \mathrm{ft}$

5) Air temperature $50 \mathrm{ft}$

6) Atmospheric pressure ground

\section{TURBINES $11,12,13$ :}

1) Field current

2) Generator power

3) Utility power

4) Generator voltage

5) Rotor speed

6) Blade \#1 pitch angle

7) Yaw error

8) Nacelle position 


\subsection{DATA SETS USED FOR THE ANALYSIS}

For the purpose of this report, a subset was created from the data collected during the April 1 to October 17, 1985, period. This subset, shown in Table 2.2, incorporated all data when the PNL 200-ft level wind speed or the BPA 195-ft level wind speed was greater than $13 \mathrm{mph}$. The periods when the winds were less than $13 \mathrm{mph}$ were not included since the turbine cut-in speed is $14 \mathrm{mph}$. All the recorded data were averaged for $1 \mathrm{~min}$ and a standard deviation for the same period was stored in a binary file. These averaged values and standard deviations are based on 1-s samples.

Figure 2.1 gives the relative positions of the turbines and towers used in this study. Figure 2.2 gives the incident wind directions for the centerline of the wake for each possible machine-on-machine and machine-on-tower wake scenario as well as the distances (in rotor diameters, D) between the structures.

TABLE 2.2. Data Channels Chosen for Analysis During Period April 1 to October 17, 1985. Included only data when wind speeds were $13 \mathrm{mph}$ or greater at either PNL 200-ft or BPA 195-ft level.
1) Year
2) Julian day
3) Hour
4) Minute
5) PNL wind speed $200 \mathrm{ft}$
6) PNL wind direction $200 \mathrm{ft}$
7) BPA wind speed $195 \mathrm{ft}$
8) BPA wind direction $195 \mathrm{ft}$
9) Turbine \#1 rotor speed
10) Turbine \#1 generator power
11) Turbine \#1 blade \#1 pitch angle
12) Turbine \#1 yaw error
13) Turbine "1 nacelle position
14) Turbine \#2 rotor speed
15) Turbine \#2 generator power
16) Turbine \#2 blade \#1 pitch angle
17) Turbine \#2 yaw error
18) Turbine \#2 nacelle position
19) Turbine $\# 3$ rotor speed
20) Turbine \#3 generator power
21) Turbine \#3 blade \#1 pitch angle
22) Turbine \#3 yaw error
23) Turbine \#3 nacelle position 


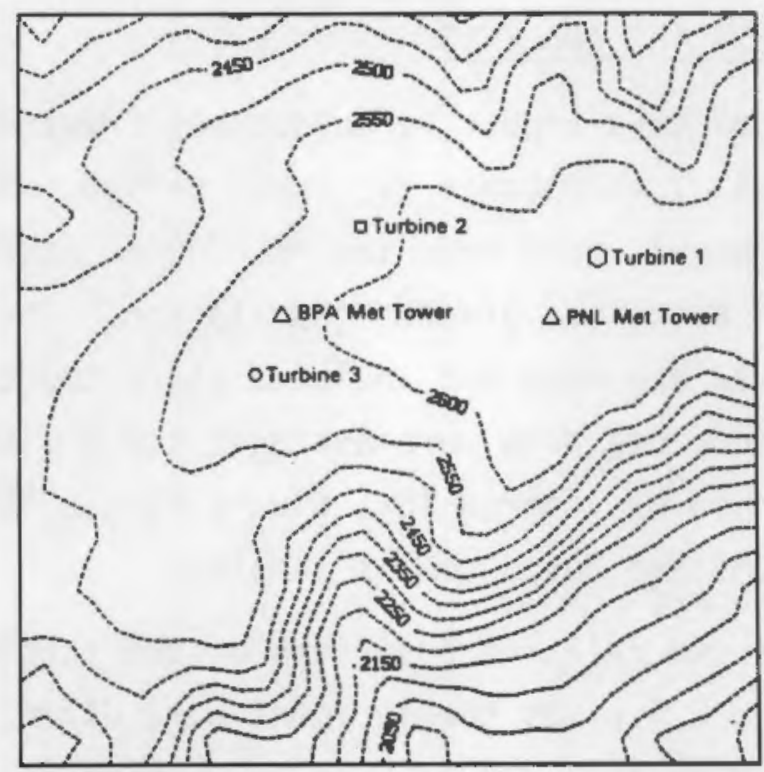

FIGURE 2.1. Relative Position of the Three MOD-2 Wind Turbines and Two Meteorological Towers at the Goodnoe Hills Site

\begin{tabular}{|c|c|c|c|c|c|}
\hline Turbine & $\# 1$ & $\# 2$ & $\# 3$ & BPA & PNL. \\
\hline$\# 1$ & .. & $\begin{array}{c}6.70 \\
96^{\circ} \\
\end{array}$ & $\begin{array}{c}10.2 \mathrm{D} \\
73^{\circ} \\
\end{array}$ & \begin{tabular}{|c|}
$9.0 \mathrm{D}$ \\
$82^{\circ}$ \\
\end{tabular} & $\begin{array}{c}2.2 \mathrm{D} \\
42^{\circ} \\
\end{array}$ \\
\hline$\| 2$ & $\begin{array}{l}6.70 \\
276^{\circ} \\
\end{array}$ & $\cdots$ & $\begin{array}{c}5.0 \mathrm{D} \\
40^{\circ}\end{array}$ & $\begin{array}{c}3.3 \mathrm{D} \\
46^{\circ}\end{array}$ & $\begin{array}{l}5.8 \mathrm{D} \\
292^{\circ} \\
\end{array}$ \\
\hline 13 & $\begin{array}{c}10.2 \mathrm{D} \\
253^{\circ}\end{array}$ & $\begin{array}{l}5.00 \\
220^{\circ}\end{array}$ & $-\cdot$ & $\begin{array}{l}1.7 \mathrm{D} \\
207^{\circ}\end{array}$ & $\begin{array}{l}\text { 8.3 D } \\
260^{\circ}\end{array}$ \\
\hline
\end{tabular}

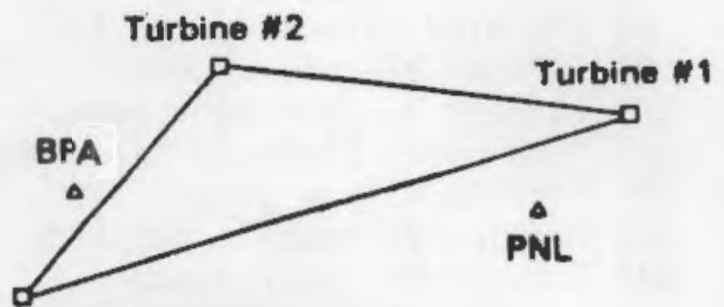

Turbine $* 3$

FIGURE 2.2. Incident Wind Directions Necessary for Centerline Wake Conditions and Distances Between Structures for All Combinations of Turbines and Towers. The relative locations of turbines and towers are also shown for reference. 


\subsection{DATA ANALYSIS AND RESULTS}

\subsection{ANALYSIS OF WAKE VELOCITY DEFICITS AND TURBULENCE CHARACTERISTICS}

In this section, wind data from the BPA and PNL. meteorological towers are evaluated to estimate the effect of a wake from an upwind turbine on the wind flow measured at a downwind tower immersed in the wake. Two consequences of the wake are examined here: the hub height velocity deficit and the turbulence intensity contrast between wake and ambient flows. These are determined by comparing the data from the PNL and BPA meteorological towers when only one of them--the PNL tower--is in a wake.

In order to properly evaluate the wake effects, it is necessary to determine the difference in the ambient flow between the two towers so that flow differences caused by the wake can be distinguished from the ambient flow differences, which may be caused by terrain effects or sensor dissimilarities. Consequently, two different data sets--a non-wake and a wake data set--were created to compare the non-wake and wake flow characteristics. These sets were formed from the wind data described in Section 2. A prerequisite for including any 1-min sample in either of these sets was that the wind speed, the speed standard deviation, and the wind direction had to be available from both the PNL $(200-\mathrm{ft})$ and BPA (195-ft) towers (i.e., no missing data); additionally, the wind speed had to be at least $13 \mathrm{mph}$ at the BPA tower. These data were subject to a number of "reasonableness" checks to assure that obviously erroneous wind observations were excluded from both of the two sets.

The non-wake data set was created by selecting wind data when the turbines were not operating or were not affecting the wind flow at the PNL and BPA towers. For example, if only Turbine \#3 was operating and the wind direction was $280^{\circ}$ or greater, then the tower data were included in the non-wake set because Turbine \#3's wake should not have affected the flow at the PNL tower. An analysis of the frequency distribution of wind directions for this set indicated that more than $90 \%$ of the winds were from the southwest through northwest, with the greatest occurrence from the west to west-northwest directions. Since the amount of data from other directions were insufficient for a detailed analysis of the wind flow characteristics, only westerly directions $\left(220^{\circ}\right.$ to $\left.340^{\circ}\right)$ were selected for further evaluation. Moreover, for 
certain easterly directions, the anemometers on the BPA and PNL towers would be in the wake of the towers, which would make the data from these directions of questionable quality. The final non-wake data set contains 6,015 samples of 1 -min-averaged wind data.

The wake data set was created by again considering only westerly wind directions $\left(220^{\circ}\right.$ to $\left.340^{\circ}\right)$ and selecting times when both Turbines \#2 and \#3 were operating. The turbines were defined as operating if they were producing more than $100 \mathrm{~kW}$ of power. Under these circumstances, the downwind PNL tower was often in the wake of Turbine \#2 or Turbine \#3, whereas the BPA tower was completely free of wake influences. Turbine \#1 was always downwind of both towers, so its operation is of no importance to the results presented in this section. The wake data set contains 30,409 samples of 1-min-averaged data.

Figure 3.1 shows frequency distributions of wind directions at both BPA and PNL towers for the non-wake and wake data sets. (These distributions-along with the other distributions presented in this section--are represented as discrete probability density functions, defined to be non-zero only at discrete values of the independent variable. The solid and dashed lines drawn between the points where the function is non-zero merely assist to outline the shape of the distributions.) In both data sets, the distributions are quite similar, although for a given flow situation, the BPA direction measurements appear to be a few degrees greater than those taken at the PNL tower. The peak occurrences of wind direction are centered near $285^{\circ}$ (PNL) and $290^{\circ}$ (BPA) in the non-wake set and $280^{\circ}$ (PNL) and $285^{\circ}$ (BPA) in the wake set. The centerline direction between the turbines and the PNL tower is $292^{\circ}$ for Turbine \#2/ PNL and $260^{\circ}$ for Turbine $\# 3 /$ PNL. Thus, it is evident from Figure 3.1 that considerably more data should be available for the Turbine \#2/PNL wake analys is than for the Turbine \#3/PNL analysis.

Figure 3.2 shows the wind speed frequency distributions for the non-wake and wake data sets. In both data sets, the most frequent occurrence of wind speeds is in the 20 - to 25 -mph range. In the non-wake distribution, the higher speeds at the PNL tower are more frequent than at the BPA tower, while in the 

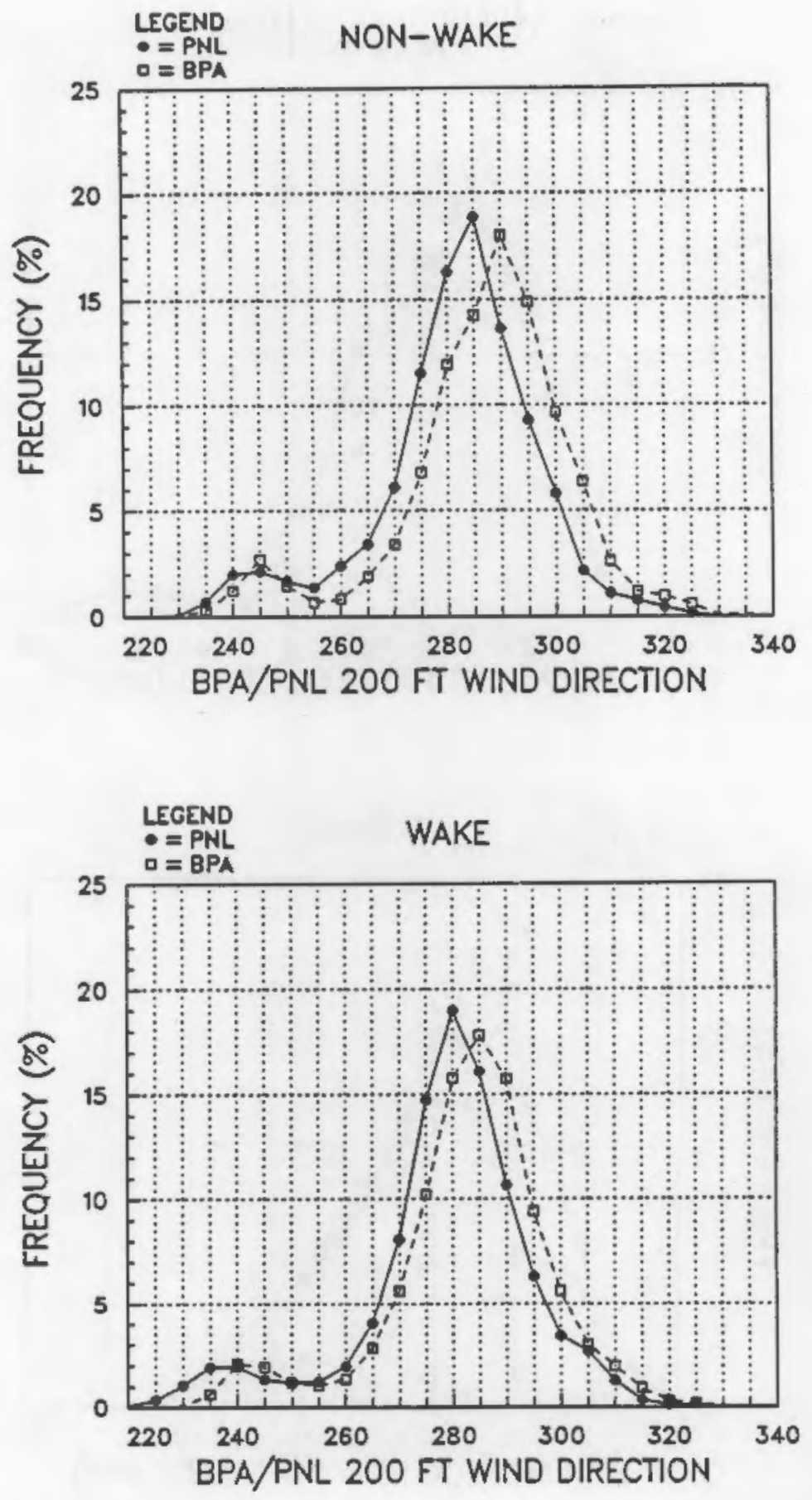

FIGURE 3.1. Non-Wake and Wake Wind Direction Frequency Distributions. The distributions are represented as discrete distributions, with values occurring in $5^{\circ}$ direction increments. The $x$-axis represents either the BPA or PNL direction. 

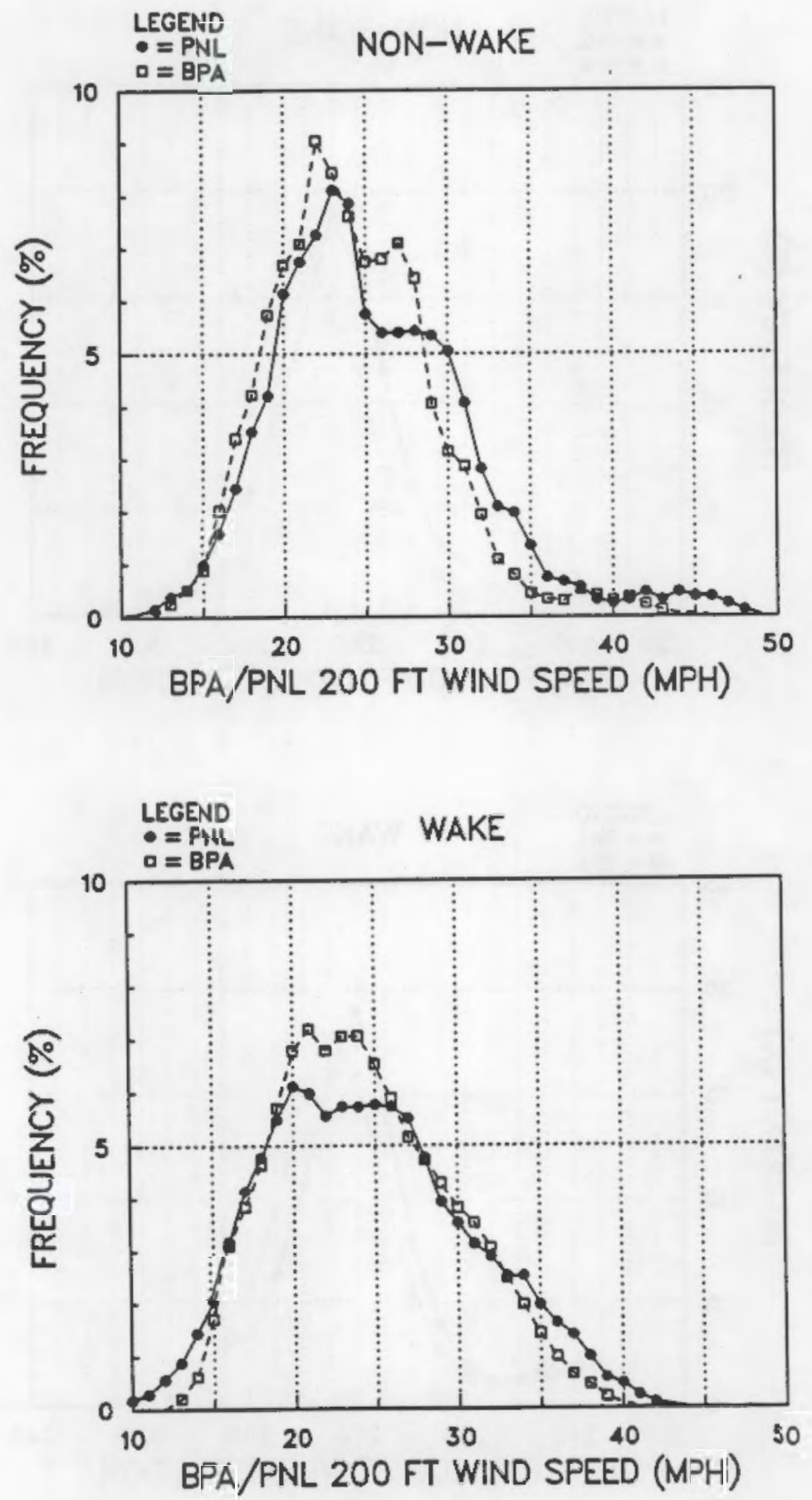

FIGURE 3.2. Non-Wake and Wake Wind Speed Frequency Distributions. The distributions are represented as discrete distributions, with speed values occurring in $1 \mathrm{mph}$ increments. The $x$-axis represents either the BPA or PNL wind speed. 
wake distribution, higher PNL speeds become comparatively less frequent; this reduction in speed is evidently caused by wakes.

Figure 3.3 shows the frequency distributions of turbulence intensity for the non-wake and wake data sets. Turbulence intensity (TI) is defined here as the standard deviation $(\sigma)$ of the 1-s samples of the wind speed for a 1-min period divided by the mean speed $(U)$ for the same period:

$$
T I=\frac{\sigma}{J} .
$$

It is evident from the non-wake distributions that turbulence intensities derived from measurements made by the BPA sensor are larger than those obtained from the PNL sensor. This dissimilarity could be caused by a difference in the response of the BPA and PNL sensors rather than different flow conditions at the two towers. (Recall that the BPA sensor is a propeller-type instrument, while the PNL sensor is a cup anemometer.) Non-wake average turbulence intensities are 0.056 and 0.077 for the PNL and BPA towers, respectively; these are fairly low. Comparison of the non-wake and wake set shows that, for the wake set, larger turbulence intensities become more frequent at the PNL tower; in fact, the average turbulence intensity increases at the PNL tower $(0.061)$ and decreases at the BPA tower $(0.071)$. As will be shown later, the turbulence intensity rise at the PNL tower is most likely caused by wakes.

Figure 3.4 shows the ratio of 200-ft PNL wind speed to 195- $\mathrm{ft}$ BPA wind speed as a function of wind direction for the wake and non-wake data sets. (The data processing involved in making this figure--and also Figure 3.6--is explained in Appendix B.) The speed ratios are plotted as a function of BPA wind direction. Nearly identical results are obtained if the PNL direction is used as the independent variable; therefore, speed ratios plotted against PNL direction will not be displayed here. As shown in Figure 3.4, maximum velocity deficits (defined here as the maximum difference between the ambient and wake speed ratios, divided by the ambient ratio) are about $25 \%$ when the wake of Turbine \#2 impinges on the PNL tower and about $12 \%$ for the wake of Turbine \#3. However, the maximum deficit occurs at a BPA wind direction of $306^{\circ}$ for the wake case of Turbine \#2/PNL (5.8 D), which is $14^{\circ}$ off the $292^{\circ}$ centerline direction between Turbine $\$ 2$ and the PNL tower. When the BPA wind direction 

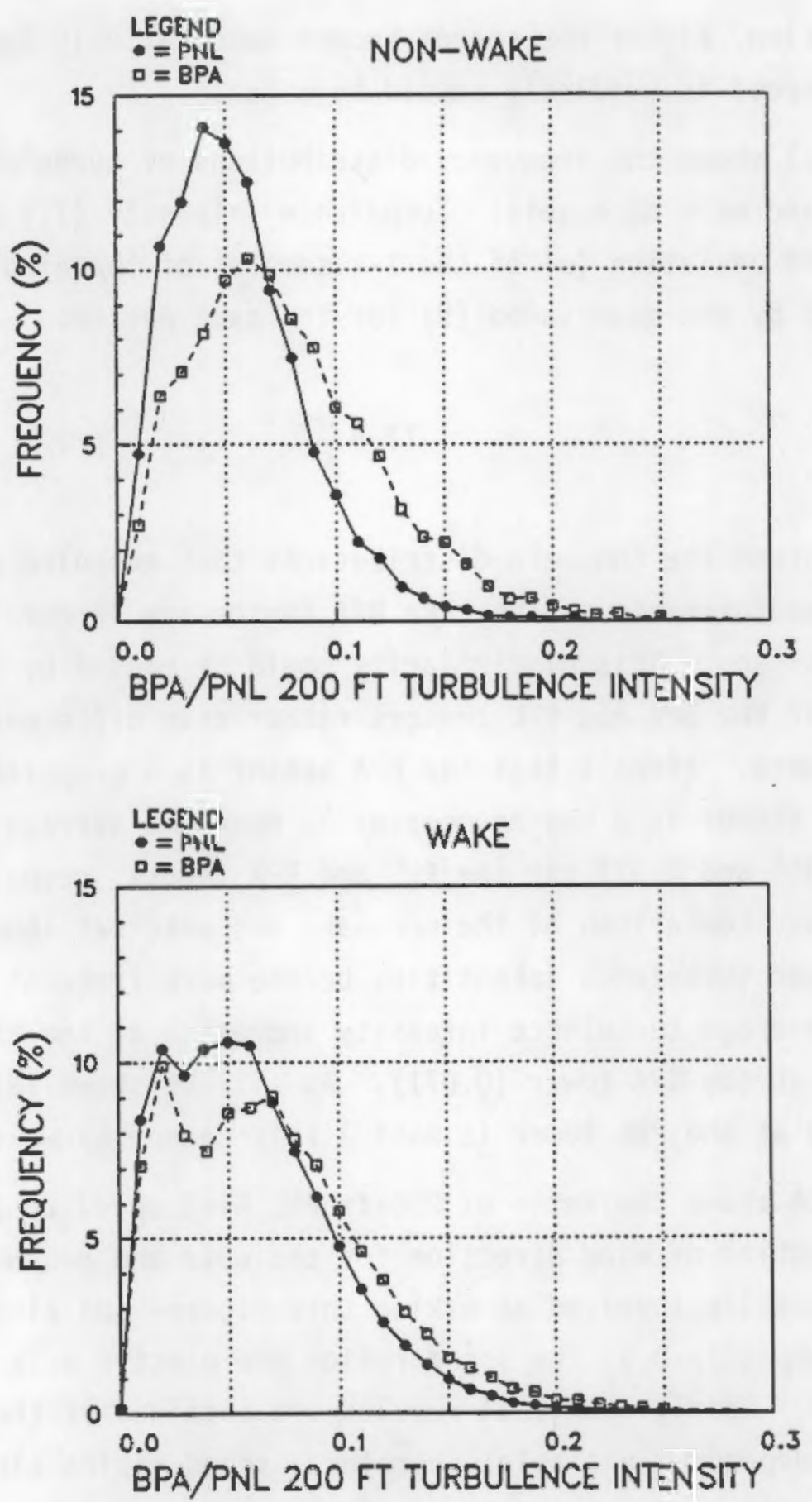

FIGURE 3.3. Non-Wake and Wake Turbulence Intensity Frequency Distributions. The distributions are represented as discrete distributions, with turbulence intensity values occurring in 0.01 increments. The $x$-axis represents either the BPA or PNL turbulence intensity. 


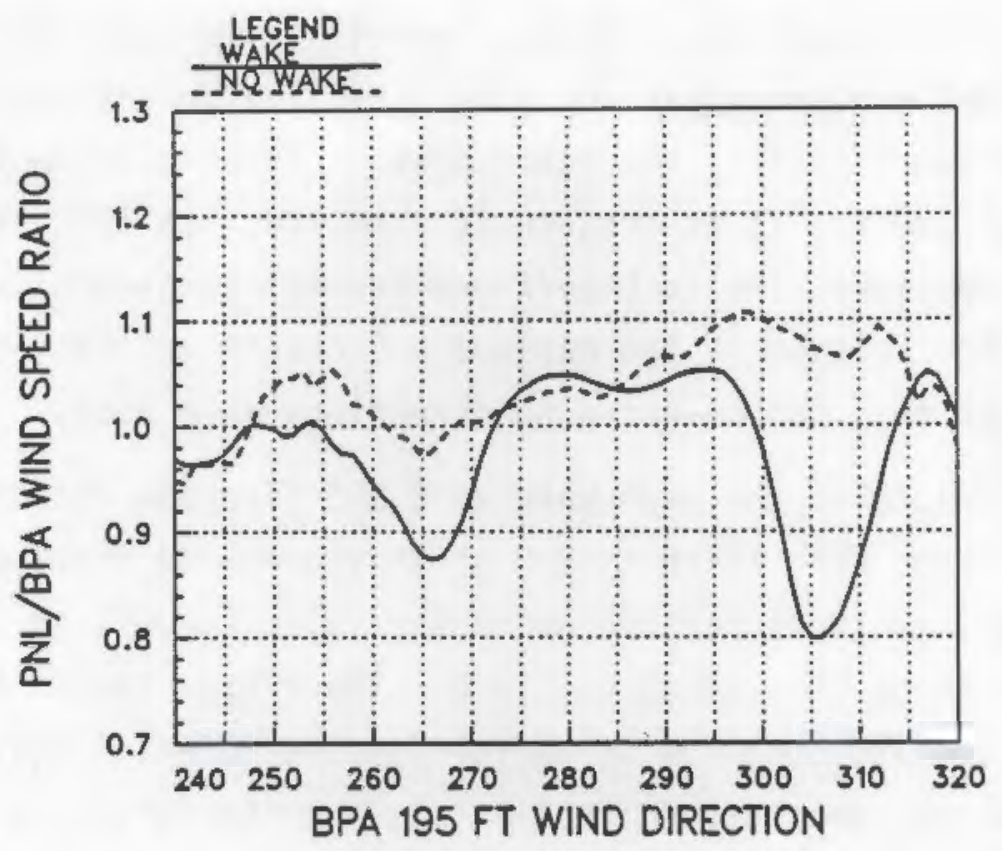

FIGURE 3.4. The Ambient (Non-Wake) and Wake Wind Speed Ratio Plotted Versus the BPA Wind Direction. The wind speed ratio is the PNL speed divided by the BPA speed.

is near the $292^{\circ}$ centerline direction, the velocity deficit is very much smaller and it appears that the PNL tower is almost completely out of the wake. For the wake case of Turbine \#3/PNL $(8.3 \mathrm{D})$, the maximum deficits are much closer to the $260^{\circ}$ centerline direction, occurring at about $266^{\circ}$.

Comparing the direction of fsets for the Turbine \#2/PNL and Turbine \#3/PNL wake cases, where the offset is defined as the discrepancy between the direction of the maximum velocity deficit and the centerline direction, one finds an appreciable difference between the offsets of about $8^{\circ}$ [i.e., $8^{\circ}=$ (Turbine \#2/PNL offset - Turbine \#3/PNL offset) $=14^{\circ}-6^{\circ}$, which remains the same regardless if the BPA or the PNL direction is used]. If the offsets were identical for both wake cases, then wind sensor or turbine/tower alignment errors may be suspected. However, the greater direction offset for the Turbine \#2/PNL wake case indicates that the wake, on the average, may be curving towards the north and not traveling in a straight line. Reasons for this curvature are not known but possible explanations include terrain effects on the flow and/or effects of directional shear (over the height of the rotor disk) on steering the wake. The majority of the strong winds from the 
west-northwest directions occur during the nighttime hours when stable atmospheric conditions are prevalent and wind direction shears are frequently $10^{\circ}$ to $15^{\circ}$ across the lower part of the rotor disk. For example, when the wind direction is $305^{\circ}$ at $200 \mathrm{ft}$, it is frequently about $290^{\circ}$ to $295^{\circ}$ at 50 to $100 \mathrm{ft}$. Under these conditions, the turbine/tower centerline direction would coincide better with the direction of the maximum hub height velocity deficit if the low-level rather than hub height wind directions were used.

The total width of the mean wake at $5.8 \mathrm{D}$ (Turbine \#2/PNL wake case) appears to be about $20^{\circ}$, which is $2 \mathrm{D}$ at this downwind distance. The width of the primary wake (that part in which the velocity deficit is at least $10 \%$ or greater) is about $15^{\circ}$, which is $1.5 \mathrm{D}$. Therefore, the width of the primary wake at $5.8 \mathrm{D}$ appears both fairly narrow (at the $200-\mathrm{ft}$ level) and intense, because the maximum velocity deficit is still quite large $(25 \%)$ at this distance.

Figure 3.5 shows the PNL/BPA wind speed ratios for the Turbine $\# 2 /$ PNL wake case classified by various (BPA) wind speed ranges. The largest velocity

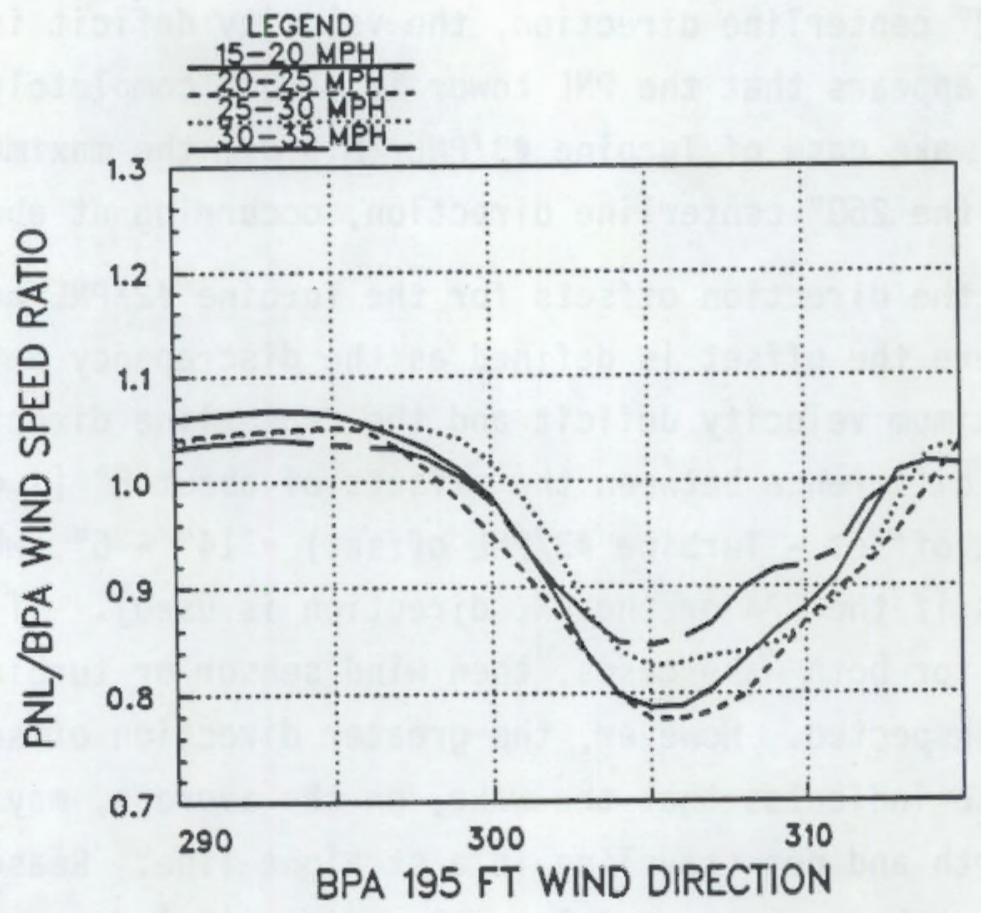

FIGURE 3.5. The PNL/BPA Wind Speed Ratio Plotted Versus BPA Wind Direction and Segregated With Respect to BPA Wind Speed for the Turbine \#2/PNL Wake Case 
deficits, which are about $27 \%$, occur at the middle (20 to $25 \mathrm{mph})$ and low (15 to $20 \mathrm{mph}$ ) wind speeds. Velocity deficits appear to decrease slightly with increasing wind speeds above $25 \mathrm{mph}$; however, even at higher wind speeds (30 to $35 \mathrm{mph}$ ) maximum velocity deficits are around $20 \%$. When determining these deficits, the ambient wind speed ratio is assumed to be constant over the four wind speed categories. This appears to be a good assumption, because the undisturbed flow in the wake data set, for example, between $290^{\circ}$ and $295^{\circ}$ in Figure 3.5, is about the same for all speed classes.

Figure 3.6 shows the PNL/BPA turbulence intensity ratio as a function of the BPA wind direction for the wake and non-wake data sets. A sharp increase of the turbulence intensity within the wake is quite evident. In non-wake conditions, turbulence intensities measured at the PNL tower are usually slightly lower than those measured at the BPA tower. However, when the PNL tower is in the wake of Turbine \#2 (5.8 D), turbulence intensities at the PNL tower are, on the average, about 2.3 times greater than those of the ambient

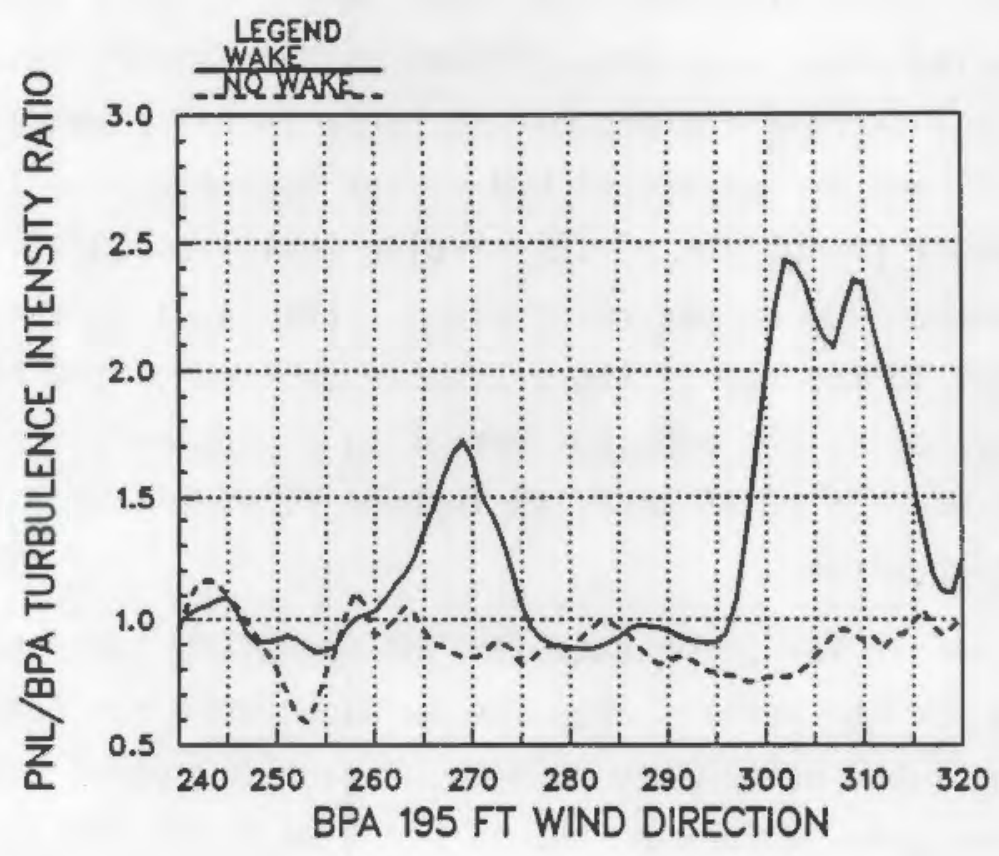

FIGURE 3.6. The Ambient (Non-Wake) and Wake Turbulence Intensity Ratio Plotted Versus BPA Wind Direction. The turbulence intensity ratio is the PNL turbulence intensity divided by the BPA turbulence intensity. 
flow measured at the BPA tower. When the PNL tower is the wake of Turbine \#3 $(8.3 \mathrm{D})$, turbulence intensities are about 1.5 times those of the ambient flow. Like the maximum velocity deficits shown in Figure 3.4, the maximum turbulence intensity ratios are about $10^{\circ}$ to $16^{\circ}$ off the turbine/tower centerline direction for the Turbine \#2/PNL wake case and about $8^{\circ}$ off the centerline for the Turbine \#3/PNL wake case. The contrast between wake and non-wake turbulence intensity ratios is much larger than the contrast between wake and non-wake speed ratios, and therefore the turbulence intensity ratio seems to be a more sensitive indicator of the angular extent of the wake than is the speed ratio.

\subsection{NON-WAKE POWER CURVES FOR THE MOD-2S AT GOODNOE HILLS}

In order to more accurately evaluate turbine wake effects, the operation and performance of the turbines without wake influences must be understood first. In this section we examine the differences between the non-wake power curves for the three MOD-2s at Goodnoe Hills. Different power curves can result because the operating characteristics of the machines are not the same or the wind characteristics that can affect power output, such as turbulence intensity and wind shear, can be different at each individual turbine site as a result of local terrain influences. Turbine $\$ 3$ was physically different from Turbines $\# 1$ and \#2 because it had vortex generators on the blades to increase the power production of the turbine (Sullivan 1984). These vortex generators spanned $100 \%$ of the rotor blade, that is, from the fixed portion of the rotor out to the tip of the pitchable portion of the blade. Turbines \#1 and \#2 were physically the same but operating characteristics were not the same in high winds ( 35 to $45 \mathrm{mph}$ ), as Turbine \#1 experienced more frequent shutdowns in high winds.

However, before the power data for the operating turbines were analyzed, the power data for the periods when the turbines were not operating were examined to check the zero power offset. Figure 3.7 shows the frequency distribution of the power data when the turbines were off, while figure 3.8 shows time series plots of the daily average zero power offsets for each turbine during the data collection period. The variation of the power offsets is caused by the drift of the zero point in the power-sensing instrumentation. It is observed in Figure 3.7 that the distributions of zero power offsets for 


\section{Turbine \#1}

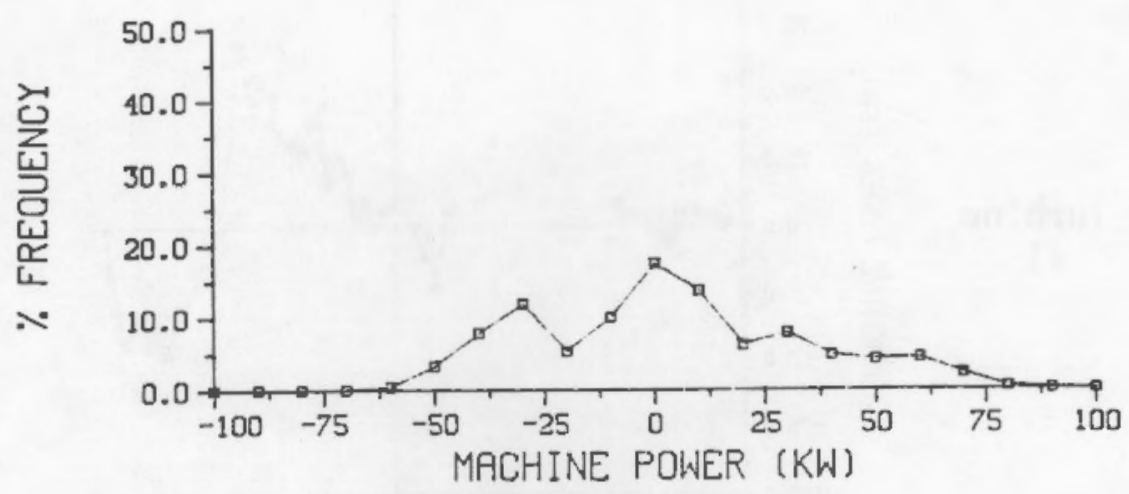

\section{Turbine \#2}

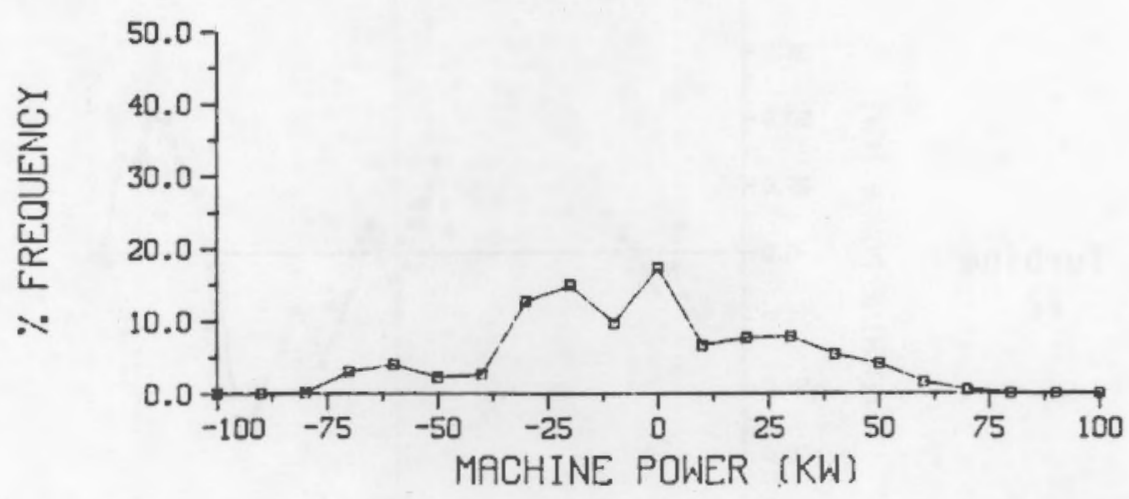

Turbine \#3

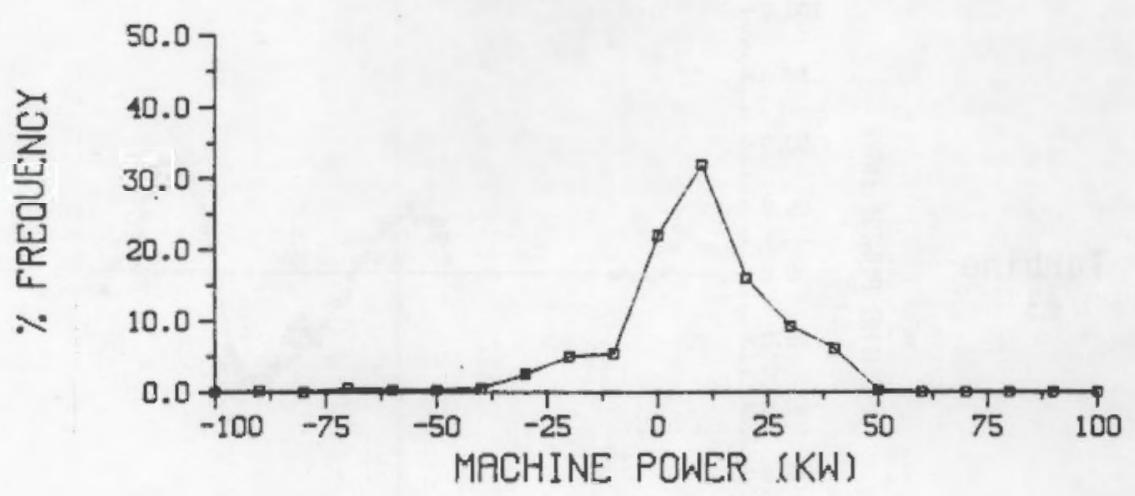

FIGURE 3.7. Frequency Distribution of Power Data (zero power offsets) When the Wind Turbines Were 0 ff for Turbines \#1, \#2, and \#3 

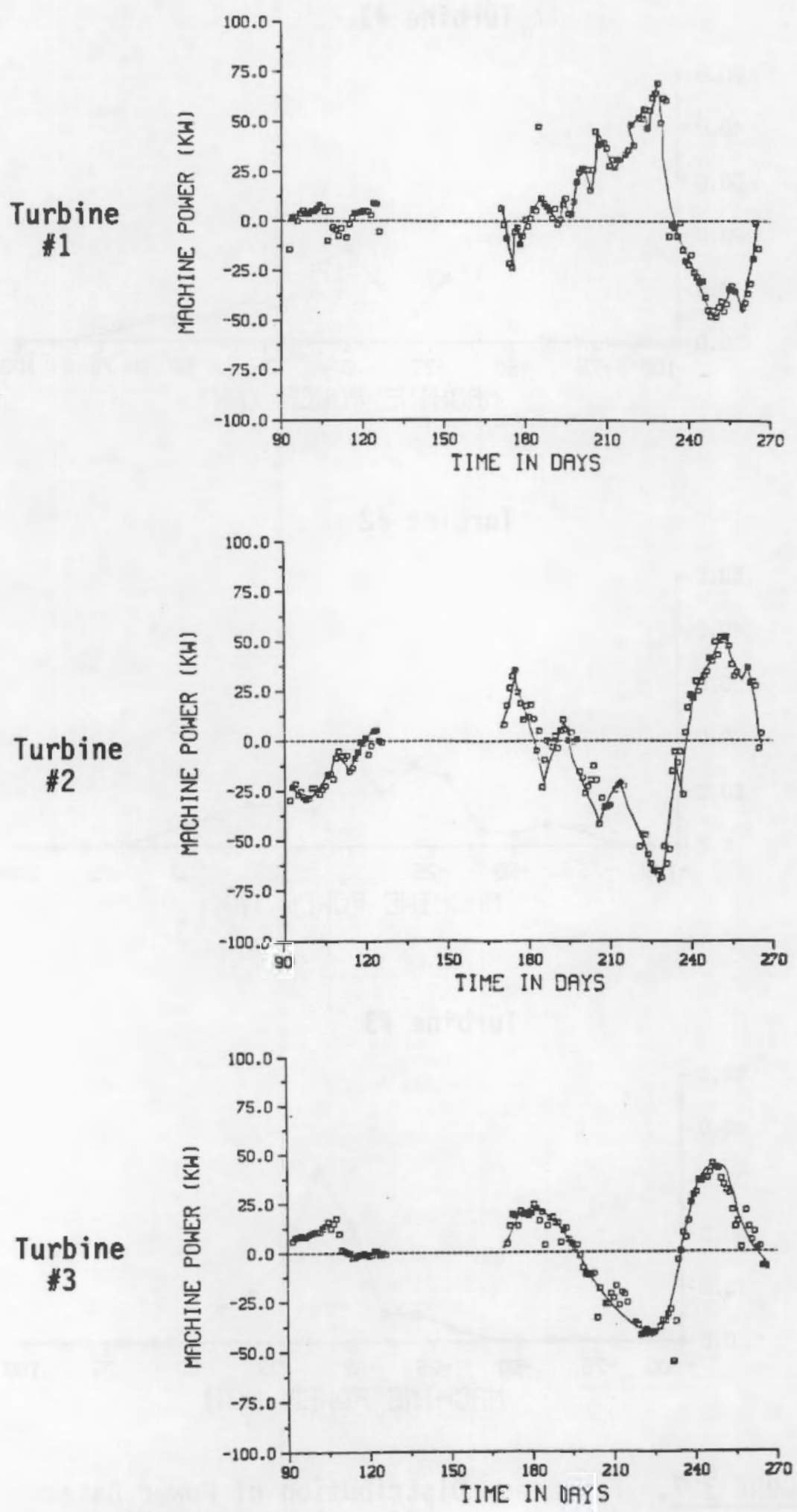

FIGURE 3.8. Time Series Plots of the Daily Average Zero Power Offsets for Turbines \#1, $\# 2$, and \#3 
Turbines \#1 and \#2 are much broader than for Turbine \#3. In Figure 3.8, the daily averaged zero power offsets vary considerably from late June to September (Julian days 170 to 260 ), as the plots show oscillations in the magnitude of the offset that vary almost from $-75 \mathrm{~kW}$ to $+75 \mathrm{~kW}$. Turbine 33 shows the smallest range of power offsets, but these still can be very significant. An attempt was made to correct for these zero power offsets by using the daily averages for each turbine to adjust the power data for each given day. Figure 3.8 indicates that these offsets usually varied only a few $\mathrm{kW}$ from day to day.

Figure 3.9 presents the non-wake power curves, when the turbines were operating, for the three MOD-2s at Goodnoe Hills using the 1985 data set. These power data are based on times when the BPA 195- $\mathrm{ft}$ wind direction was between $220^{\circ}$ and $320^{\circ}$ (because the BPA tower was completely free of wake influences at these directions), the BPA wind speed was $15 \mathrm{mph}$ or greater, and the turbine in question was free of wake influences. The PNL tower was often downwind of Turbines $\# 2$ and \#3 and frequently in the turbines' wakes. The power data, which have been corrected for zero power offsets, were converted to sea level and an upper limit of $2500 \mathrm{~kW}$ was set for the power output. The bins are based on 1-min averages with the wind speed intervals being $1 \mathrm{mph}$ centered on the integer value. The standard deviation of power for each bin is also plotted in Figure 3.9. The number of 1-min samples of non-wake power data for Turbines $\# 1, \# 2$, and $\# 3$ are $22,615,48,462$, and 58,230 , respectively. Turbine \#1 had considerably fewer non-wake power data than Turbines \#2 and \#3 because it was often in the wakes of Turbines \#2 and \#3. Also, at speeds above $35 \mathrm{mph}$, power data were even more limited for Turbine \#1 because of more frequent shutdowns in high winds.

Figure 3.10 presents a comparison of the non-wake power curves for the three turbines. Average differences in power output between Turbines \#1 and \#2 are quite small ( $3 \%)$, except at low speeds ( 15 to $18 \mathrm{mph}$ ) when Turbine \#1 produced up to 10 to $20 \%$ more power than Turbine $\# 2$. For wind speeds between 20 and $38 \mathrm{mph}$, Turbine \#3 produced more power than \#1 or \#2. The largest percentage differences are from 24 to $31 \mathrm{mph}$, when Turbine $\# 3$ produced $10 \%$ to $13 \%$ more power than Turbines $\# 1$ and $\# 2$. This can be explained by the fact that the vortex generators on the blades of Turbine \#3 increase power output 

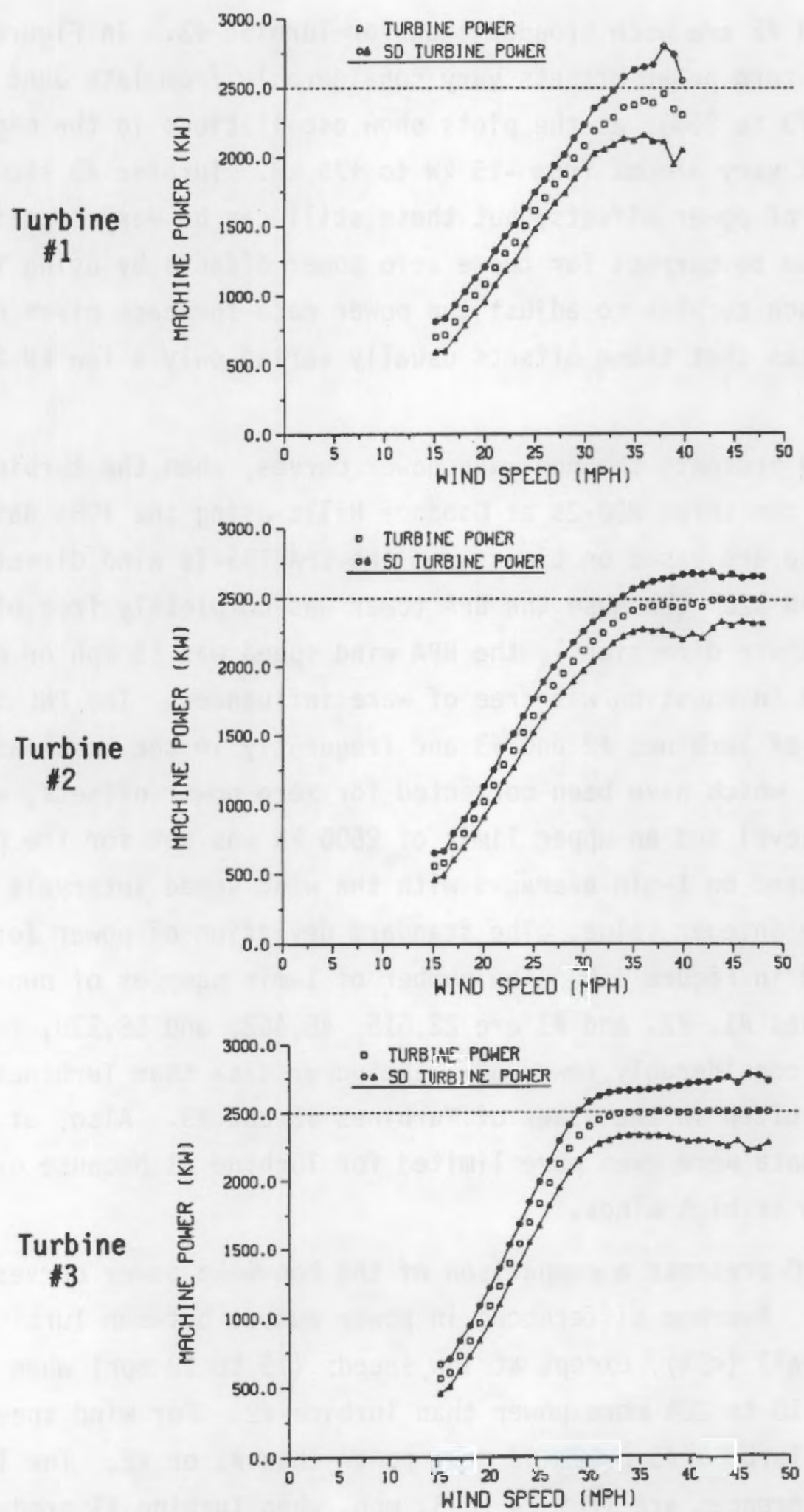

FIGURE 3.9. Non-Wake Power Curves, as a Function of BPA $195-\mathrm{ft}$ Wind Speed for Turbines $\# 1, \# 2$, and $\# 3$ 


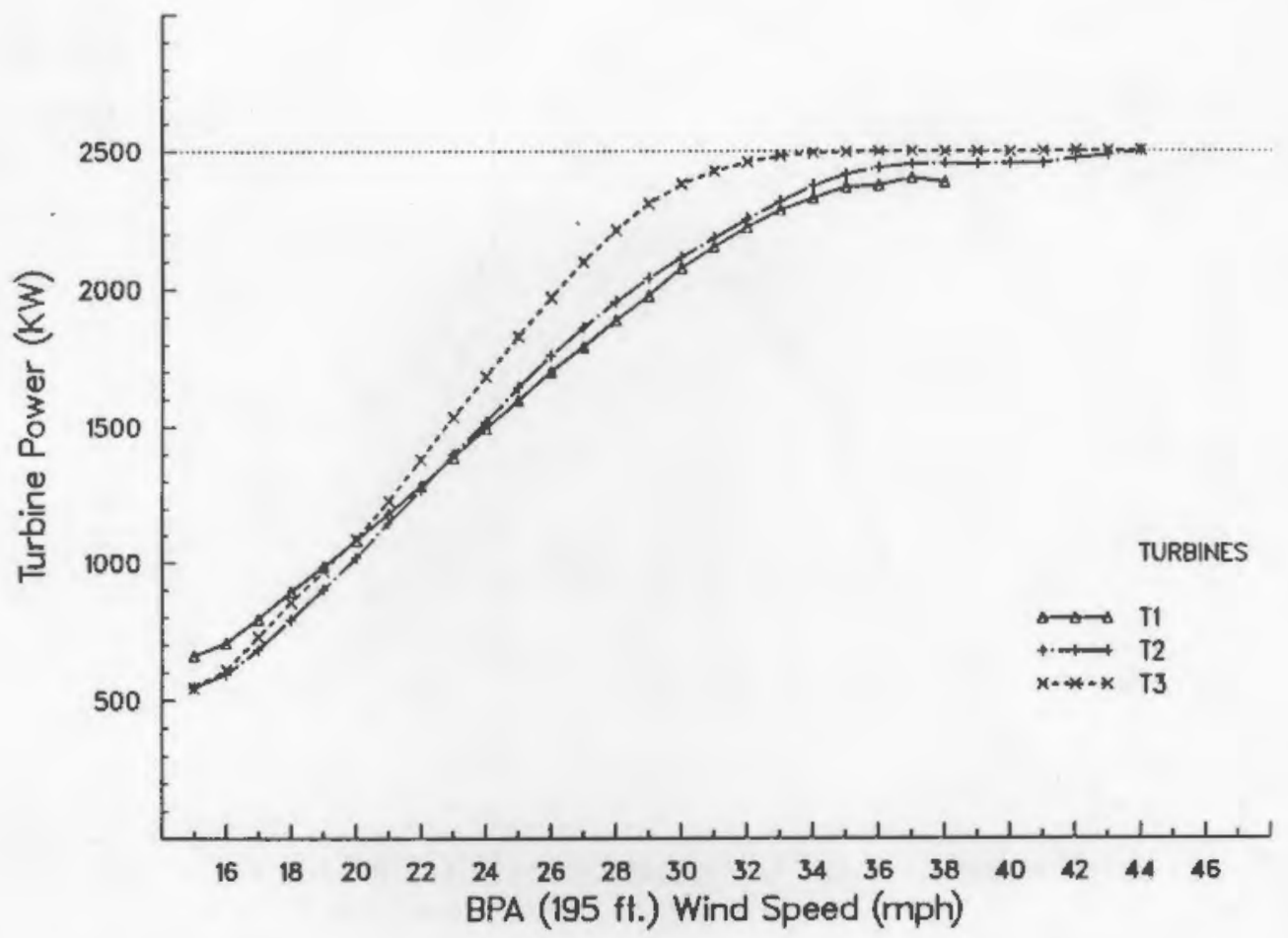

FIGURE 3.10. Comparison of the Non-Wake Power Output for Turbines $\# 1, \# 2$, and \#3

and reduce the wind speed at which rated power is reached (Sullivan 1984). This increased power output at Turbine $\# 3$ is further exemplified in Figure 3.11 , which shows that Turbine $\$ 3$ produced as much as 250 to $300 \mathrm{~kW}$ more power than Turbines \#1 or \#2 at wind speeds of 28 to $30 \mathrm{mph}$.

So $f a r$, we have examined the average power production as a function of wind speed for each wind turbine and have identified variations in power output that are associated with physical differences between the machines and different operating characteristics. Now, we also examine the variability of power production as a function of turbulence intensity. First, however, in order to stratify the power output by turbulence intensity, we need to select suitable categories of turbulence intensity for the Goodnoe Hills site. Based on the frequency distributions of turbulence intensities for the BPA tower (see Figure 3.3), four categories of turbulence intensity were established for use in stratifying the analyses of turbine power production. These categories of turbulence intensity are: low $(0.00$ to 0.05$)$, mid $(0.05$ to 0.10$)$, mid-high $(0.10$ to 0.15$)$, and high $(0.15$ to 0.30$)$. 


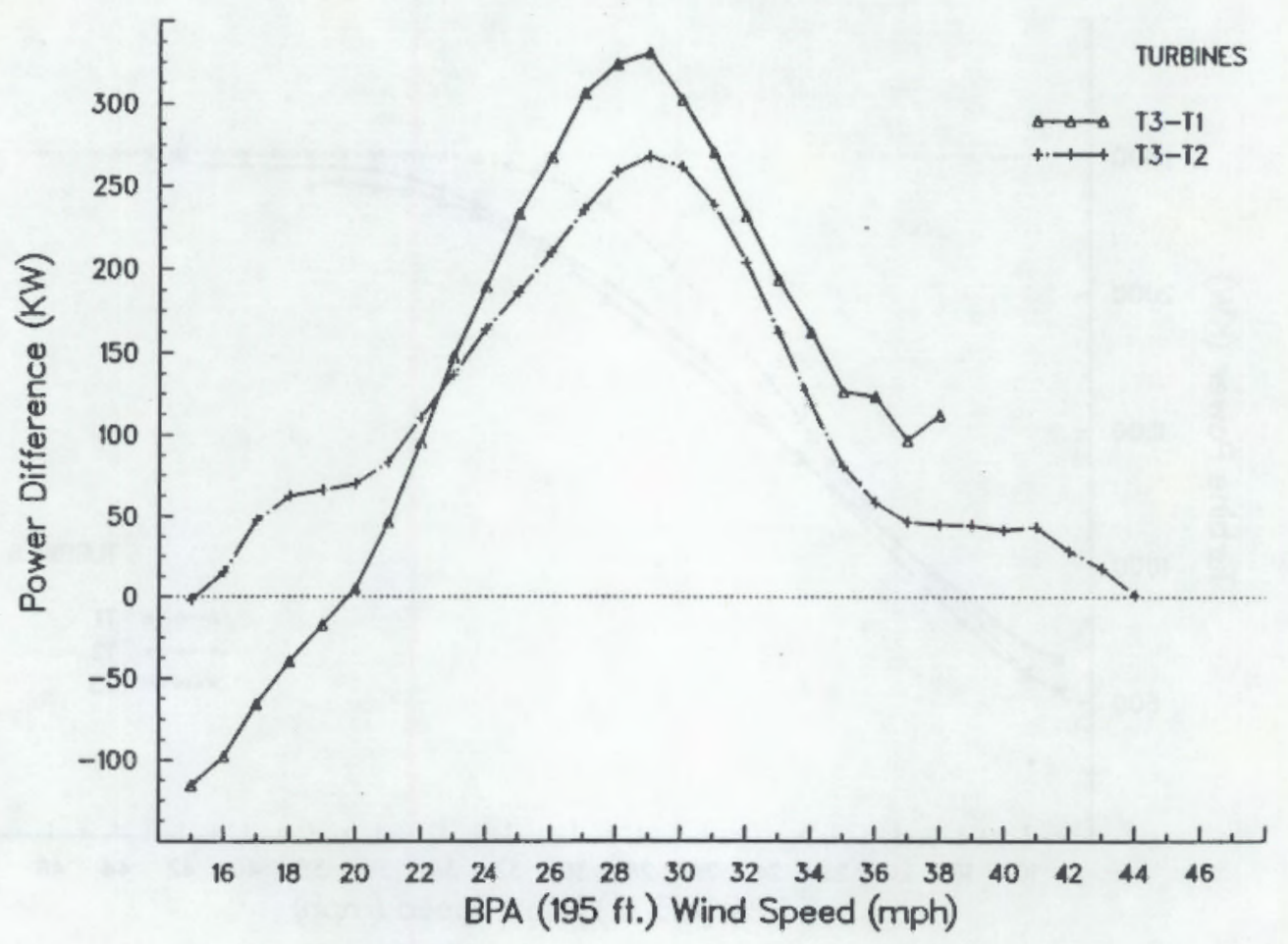

FIGURE 3.11. Difference in Power Output (Non-Wake) for Turbines \#1, \#2, and \#3

The analyses of power production as a function of wind speed and for the four different turbulence intensity categories are shown for each wind turbine in Figure 3.12. Only non-wake data from periods when each turbine was not in the wake of an upwind turbine were used in these analyses. At speeds below rated, it is very apparent that, for a given wind speed, the MOD-2's power production increases as turbulence intensity increases. The differences in power production are quite dramatic between the highest and lowest turbulence intensity categories. For example, at Turbine \#2 the average power output in a 20-mph wind speed was $865 \mathrm{~kW}$ for the lowest turbulence intensity $(0.00$ to 0.05 ) and $1400 \mathrm{~kW}$ for the highest turbulence intensity $(0.15$ to 0.30$)$. At Turbine 2 , the average difference in power output between the highest and lowest turbulence intensities was comparable to that of about a 4-mph difference in the wind speed (e.g., the power output at $20 \mathrm{mph}$ for the highest turbulence intensity is about the same as that at $24 \mathrm{mph}$ for the lowest turbulence intensity). At Turbines $\# 1$ and $\# 3$, these differences were slightly smaller and comparable to that of about a 3 -mph difference in wind speed. 

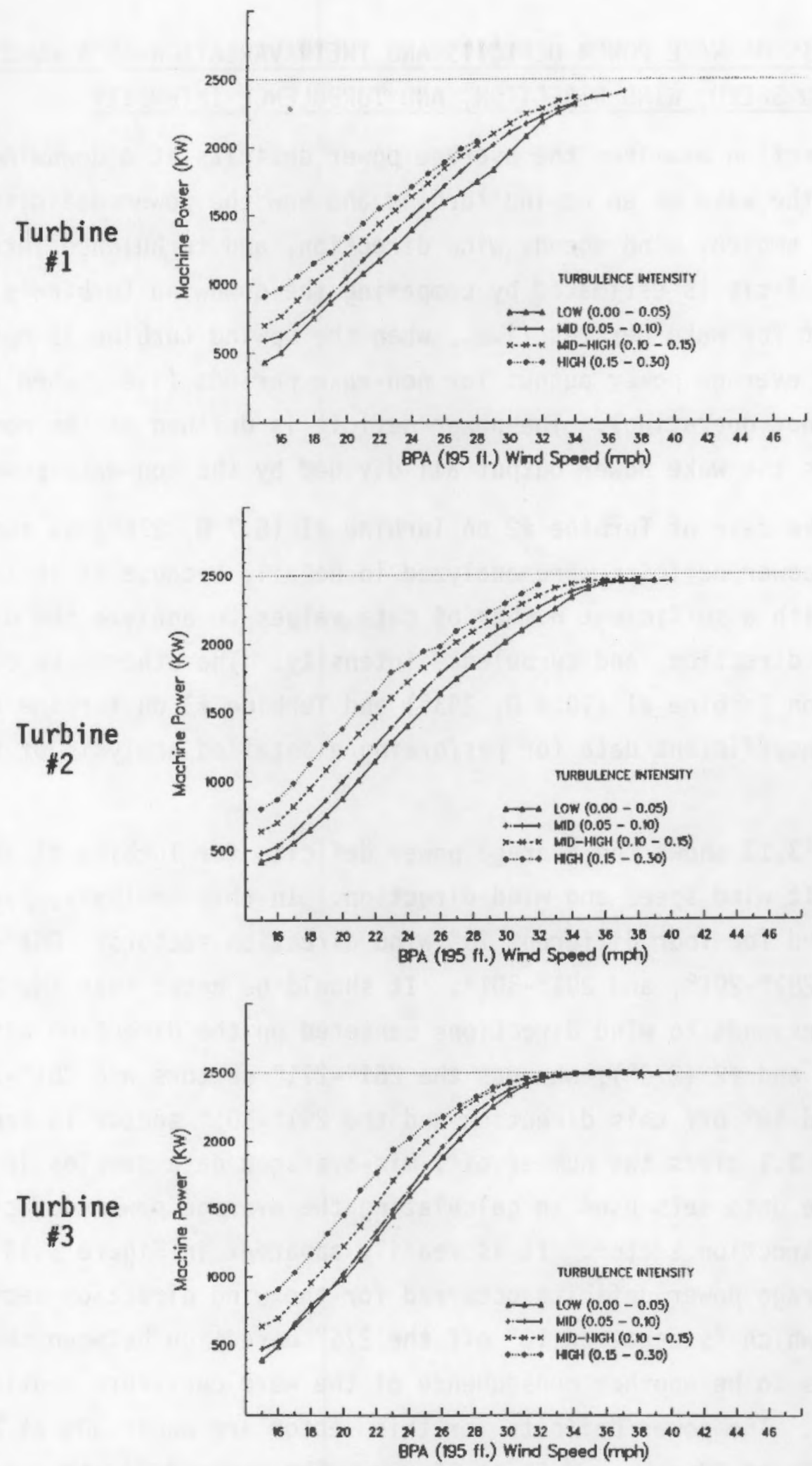

FIGURE 3.12. Non-Wake Power Output as a Function of Wind Speed and Turbulence Intensity for Turbines \#1, \#2, and \#3 


\subsection{ANALYSIS OF WAKE POWER DEFICITS AND THEIR VARIATION AS A FUNCTION OF WIND SPEED, WIND DIRECTION, AND TURBULENCE INTENSITY}

This section examines the average power deficits at a downwind turbine that is in the wake of an upwind turbine and how the power deficits vary as a function of ambient wind speed, wind direction, and turbulence intensity. The power deficit is estimated by comparing the downwind turbine's average power output for wake periods (i.e., when the upwind turbine is operating) against its average power output for non-wake periods (i.e., when the upwind turbine is not operating). The power deficit is defined as the non-wake power output minus the wake power output all divided by the non-wake power output.

The wake case of Turbine \#2 on Turbine $\# 1\left(6.7 \mathrm{D}, 276^{\circ}\right)$ is the only wake case where power deficits were analyzed in detail, because it is the only wake case with a sufficient number of data values to analyze the data by wind speed, wind direction, and turbulence intensity. The other wake cases, Turbine 3 on Turbine $\# 1\left(10.3 \mathrm{D}, 253^{\circ}\right)$ and Turbine $\# 3$ on Turbine $\# 2$ (5.0 D, $220^{\circ}$ ) had insufficient data for performing a detailed analysis of the power deficits.

Figure 3.13 shows the average power deficits for Turbine $\# 1$ as a function of BPA 195-ft wind speed and wind direction. In this analysis, power deficits were examined for four different $10^{\circ}$ wind direction sectors: $261^{\circ}-271^{\circ}$, $271^{\circ}-281^{\circ}, 281^{\circ}-291^{\circ}$, and $291^{\circ}-301^{\circ}$. It should be noted that the $271^{\circ}-281^{\circ}$ sector corresponds to wind directions centered on the direction between Turbines $\# 1$ and $\# 2\left(276^{\circ}\right)$, whereas the $261^{\circ}-271^{\circ}$ sectors and $281^{\circ}-291^{\circ}$ sectors are centered $10^{\circ}$ off this direction and the $291^{\circ}-301^{\circ}$ sector is centered $20^{\circ}$ off. Table 3.1 gives the number of 1-min-averaged data samples in the wake and non-wake data sets used in calculating the average power deficits for each wind direction sector. It is readily apparent in Figure 3.13 that the maximum average power deficits occurred for the wind direction sector $281^{\circ}-291^{\circ}$, which is centered $10^{\circ}$ off the $276^{\circ}$ direction between the turbines. This appears to be another consequence of the wake curvature mentioned in Section 3.1. The power deficits for this sector are about $30 \%$ at $20 \mathrm{mph}, 16 \%$ at $25 \mathrm{mph}, 9 \%$ at $30 \mathrm{mph}$, and $5 \%$ at $35 \mathrm{mph}$. The power deficits are considerably less for the other direction sectors, and no deficit at all is evident for 


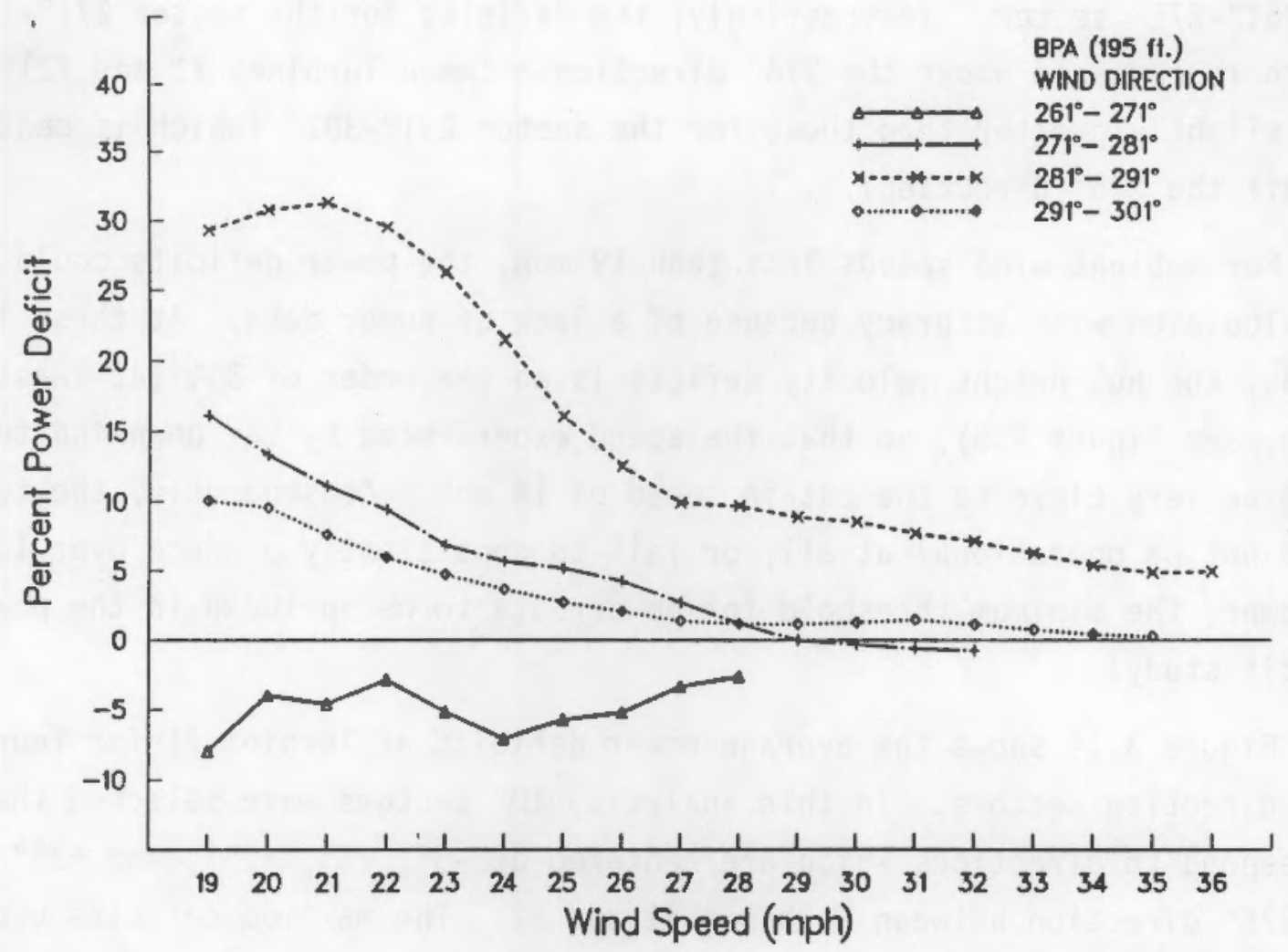

FIGURE 3.13. Average Power Deficits for Turbine \#1 Downwind of Turbine "2 $\left(6.7 \mathrm{D}, 276^{\circ}\right)$ as a Function of BPA 195-ft Wind Speed and Direction Sector

TABLE 3.1. Number of 1-min-Averaged Samples of Power Data for the Wind Direction Sectors in Figure 3.13

\begin{tabular}{|c|c|c|}
\hline $\begin{array}{c}\text { Wind } \\
\text { Direction }\end{array}$ & $\begin{array}{l}\text { Non-Wake } \\
\text { Samples }\end{array}$ & $\begin{array}{c}\text { Wake } \\
\text { Samples }\end{array}$ \\
\hline $261^{\circ}-271^{\circ}$ & 1,136 & 3,932 \\
\hline $271^{\circ}-281^{\circ}$ & 3,294 & 8,475 \\
\hline $281^{\circ}-291^{\circ}$ & 4,846 & 10,320 \\
\hline $291^{\circ}-301^{\circ}$ & 5,518 & 4,157 \\
\hline
\end{tabular}


the $261^{\circ}-271^{\circ}$ sector. Interestingly, the deficits for the sector $271^{\circ}-281^{\circ}$ (which is centered about the $276^{\circ}$ direction between Turbines $\# 1$ and $\# 2$ ) are only slightly greater than those for the sector $291^{\circ}-301^{\circ}$ (which is centered $20^{\circ}$ off the $276^{\circ}$ direction).

For ambient wind speeds less than $19 \mathrm{mph}$, the power deficits could not be calculated with accuracy because of a lack of power data. At these low speeds, the hub height velocity deficit is on the order of $30 \%$ (at least at $5.8 \mathrm{D}$, see Figure 3.5), so that the speed experienced by the downwind turbine would be very close to the cut-in speed of $14 \mathrm{mph}$. Consequently, the turbine would not be operational at all, or fail to consistently produce over $100 \mathrm{~kW}$ of power, the minimum threshold for power data to be included in the power deficit study.

Figure 3.14 shows the average power deficits at Turbine $\# 1$ for four other wind direction sectors. In this analysis, $10^{\circ}$ sectors were selected that correspond to directions which are centered at $-5^{\circ},+5^{\circ},+15^{\circ}$, and $+25^{\circ}$ off the $276^{\circ}$ direction between Turbines $\# 1$ and $\# 2$. The maximum deficits occurred for the $286^{\circ}-296^{\circ}$ sector, which is centered at $+15^{\circ}$ off the $276^{\circ}$ direction between Turbines $\# 1$ and $\# 2$. The deficits at $+25^{\circ}$ off $\left(296^{\circ}-306^{\circ}\right)$ are slightly greater than those at only $-5^{\circ}$ off $\left(266^{\circ}-276^{\circ}\right)$ the $276^{\circ}$ direction between Turbines $\# 1$ and $\# 2$. Table 3.2 gives the number of 1 -min-averaged data samples in the wake and non-wake data sets used in calculating the average power deficits for each wind direction sector.

Figure 3.15 shows a composite of the cross-wake profile of the average power deficits at Turbine $\# 1$, based on the analyses of the deficits by the various $10^{\circ}$ wind direction sectors. It is evident from this figure that the maximum average power deficits occur when the BPA $195-\mathrm{ft}$ wind directions are around $286^{\circ}$ to $288^{\circ}$, which is $10^{\circ}$ to $12^{\circ}$ off the $276^{\circ}$ centerline direction between Turbines $\# 1$ and \#2. Although the maximum deficits decrease with increasing wind speed, the direction of maximum deficits is nearly identical for all wind speeds. Maximum power deficits are $32 \%$ at $20 \mathrm{mph}, 17 \%$ at $25 \mathrm{mph}$, and $9 \%$ at $30 \mathrm{mph}$. The total width of the composite wake at $6.7 \mathrm{D}$ is about $25^{\circ}$ to $30^{\circ}$ for wind speeds around $20 \mathrm{mph}$ and about $15^{\circ}$ for wind speeds around $30 \mathrm{mph}$. 


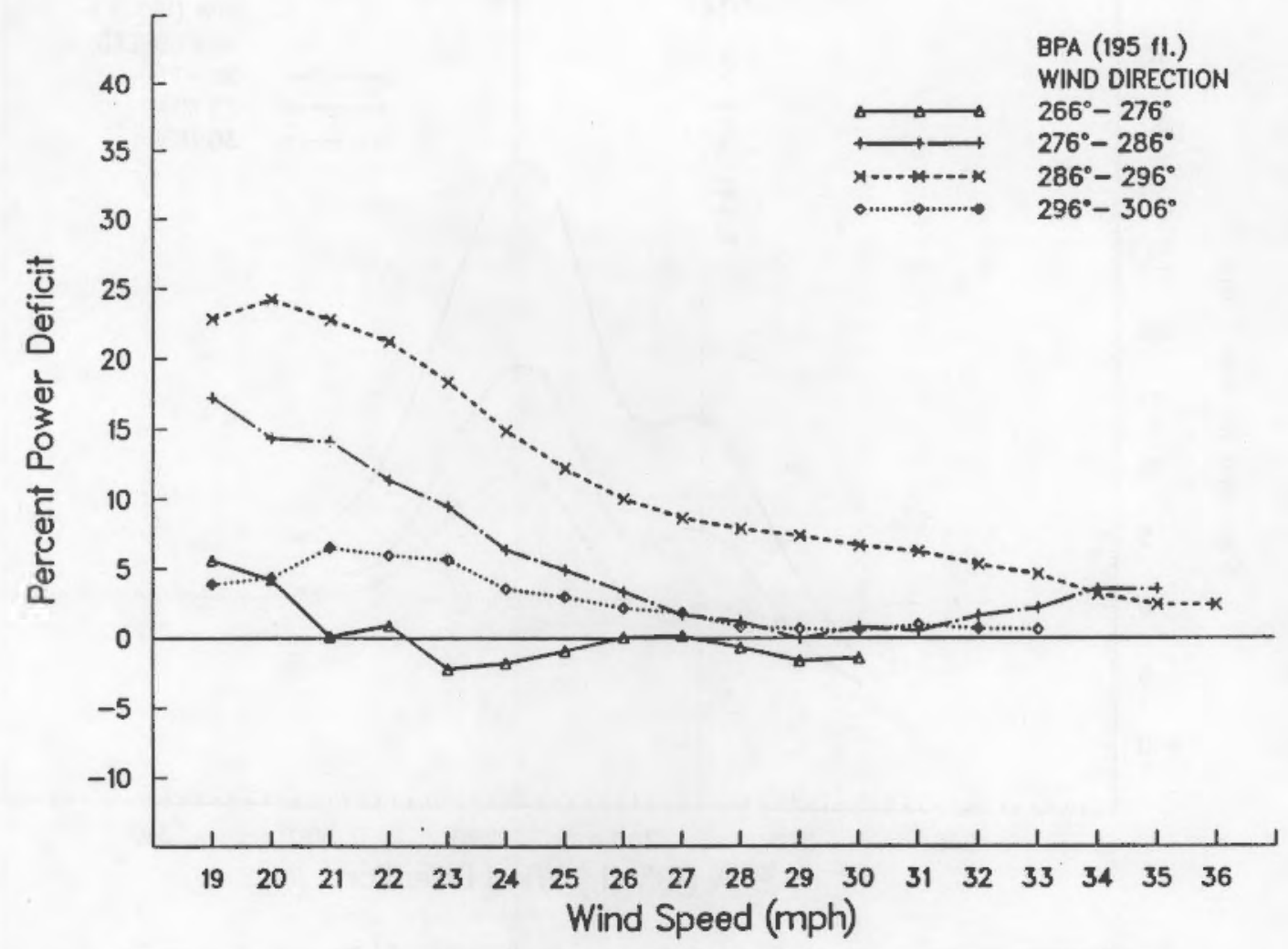

FIGURE 3.14. Average Power Deficits for Turbine \#1 Downwind of Turbine \#2 $\left(6.7 \mathrm{D}, 276^{\circ}\right)$ as a Function of BPA 195-ft Wind Speed and Direction Sector

TABLE 3.2. Number of 1-min-Averaged Samples of Power Data for the Wind Direction Sectors in Figure 3.14

\begin{tabular}{|c|c|c|}
\hline $\begin{array}{l}\text { Wind } \\
\text { Direction }\end{array}$ & $\begin{array}{l}\text { Non-Wake } \\
\text { Samples }\end{array}$ & $\begin{array}{l}\text { Wake } \\
\text { Samples }\end{array}$ \\
\hline $266^{\circ}-276^{\circ}$ & 2,023 & 5,731 \\
\hline $276^{\circ}-286^{\circ}$ & 4,650 & 5,074 \\
\hline $286^{\circ}-296^{\circ}$ & 6,055 & 7,692 \\
\hline $296^{\circ}-306^{\circ}$ & 2,630 & 1,862 \\
\hline
\end{tabular}




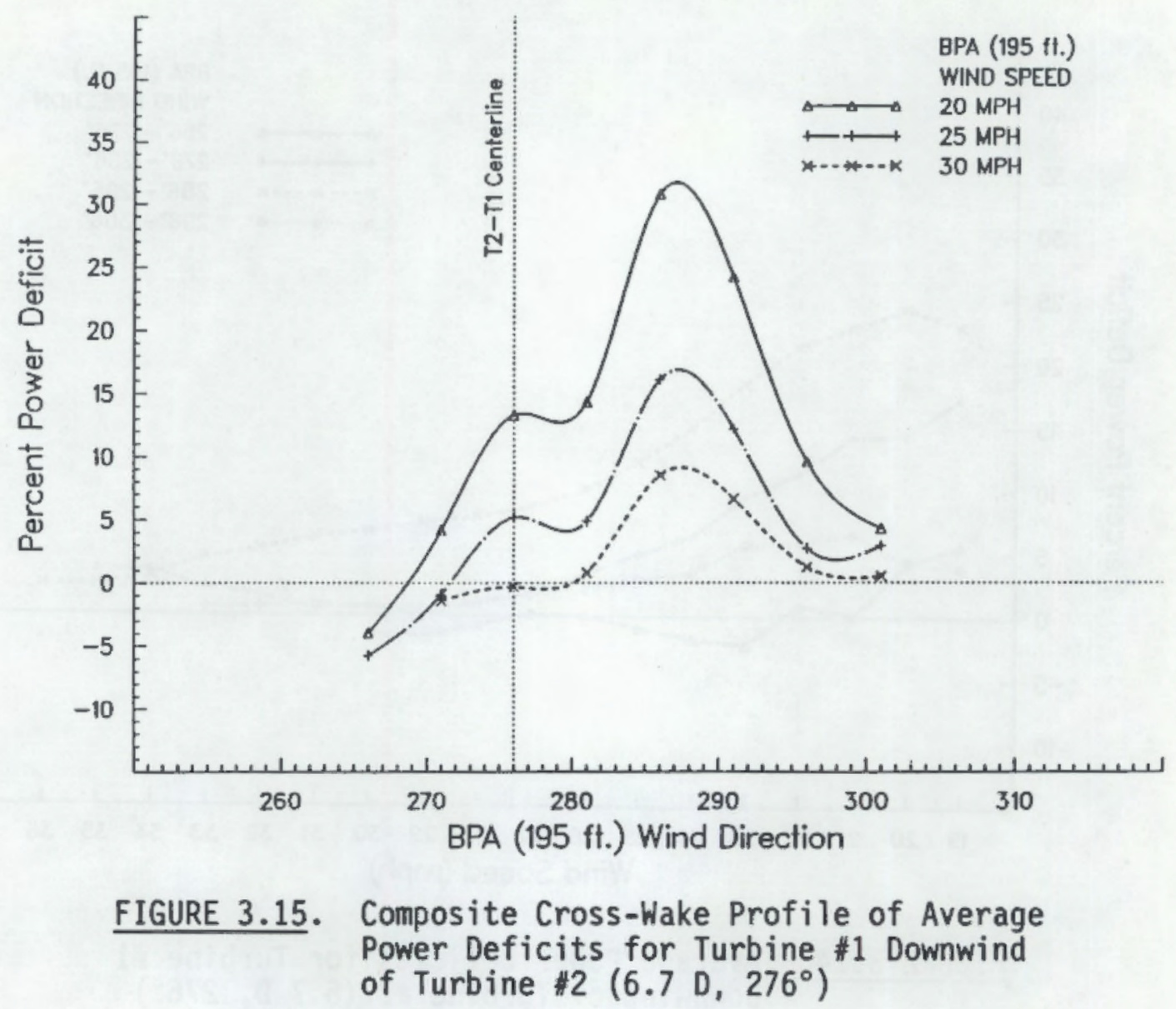

Figure 3.16 shows the average power deficits for Turbine \#1 stratified by turbulence intensity categories, for the $10^{\circ}$ wind direction sector of $281^{\circ}-291^{\circ}$. This is the sector which had the maximum power deficits. It is evident that the largest power deficits occur when the ambient turbulence intensity is low $(0.00$ to 0.05$)$. Average power deficits decrease with increasing turbulence intensity. For the lowest turbulence intensity category (0.00-0.05), power deficits were $43 \%$ at $20 \mathrm{mph}, 28 \%$ at $25 \mathrm{mph}$, and $10 \%$ at $30 \mathrm{mph}$. For the mid-high turbulence category $(0.10$ to 0.15$)$, power deficits were $23 \%$ at $20 \mathrm{mph}, 9 \%$ at $25 \mathrm{mph}$, and $6 \%$ (estimated) at $30 \mathrm{mph}$. Thus, especially for wind speeds in the $19-$ to 28 -mph range, there is a substantial difference in the average power deficits between the low and mid-high turbulence intensity categories. Table 3.3 gives the number of 1-min-averaged data samples in the wake and non-wake data sets used in calculating the average power deficits for each turbulence intensity category. For high turbulence 


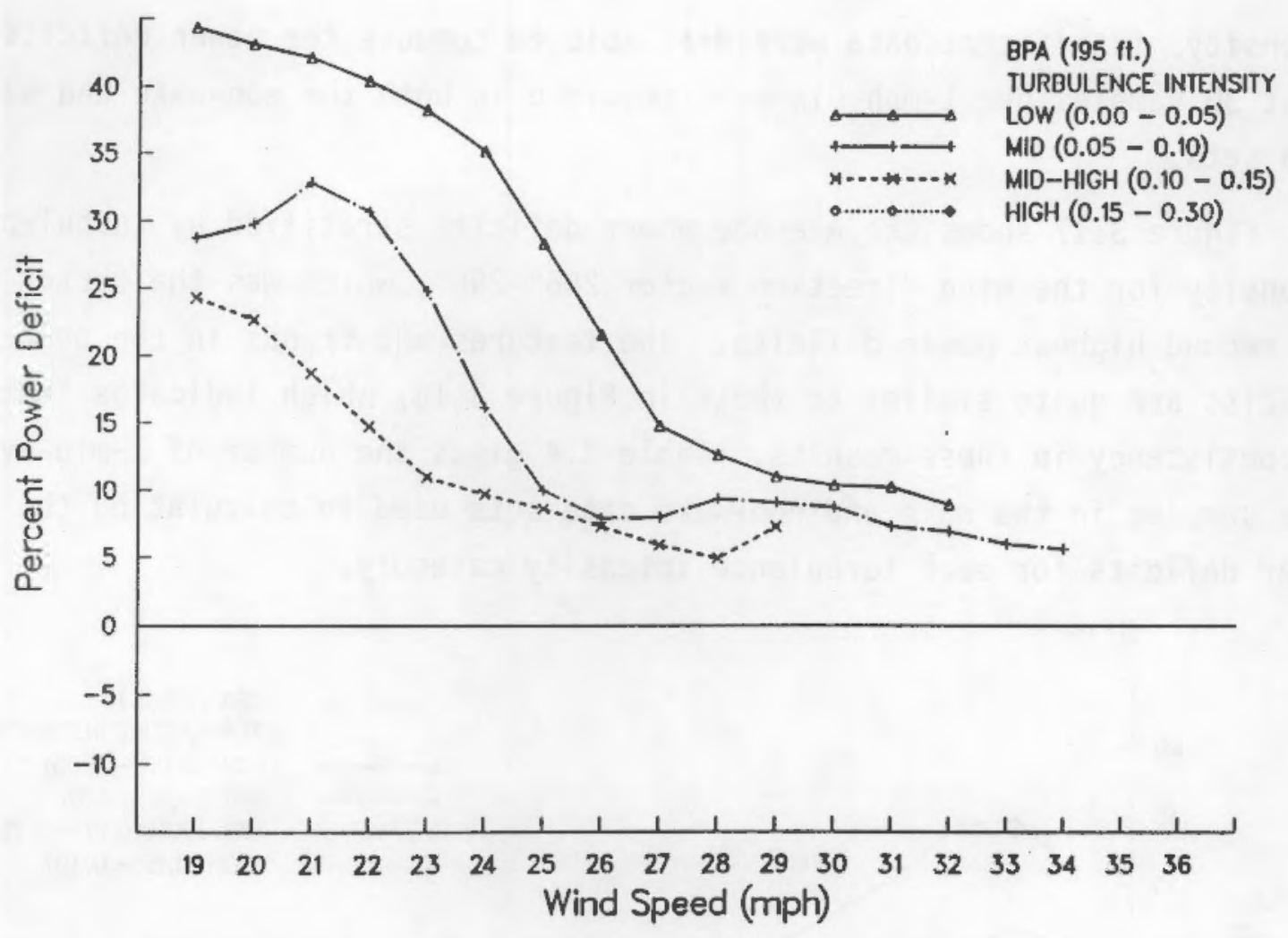

FIGURE 3.16. Average Power Deficits as a Function of Ambient Turbulence Intensity and Wind Speed for Turbine \#1 Downwind of Turbine $\# 2\left(6.7 \mathrm{D}, 276^{\circ}\right)$ for the Wind Direction Sector $281^{\circ}-291^{\circ}$

TABLE 3.3. Number of 1-min-Averaged Samples of Power Data in Wind Direction Sector $281^{\circ}-291^{\circ}$ for the Turbulence Intensity Categories in Figure 3.16

\begin{tabular}{|c|c|c|}
\hline $\begin{array}{l}\text { Turbulence } \\
\text { Intensity }\end{array}$ & $\begin{array}{l}\text { Non-Wake } \\
\text { Samples } \\
\end{array}$ & $\begin{array}{c}\text { Wake } \\
\text { Samples }\end{array}$ \\
\hline Low & 1,871 & 3,925 \\
\hline Mid & 2,078 & 4,223 \\
\hline Mid-High & 726 & 1,742 \\
\hline High & 260 & 568 \\
\hline
\end{tabular}


intensity, insufficent data were available to compute the power deficits. At least 30 samples per 1-mph bin were required in both the non-wake and wake data sets.

Figure 3.17 shows the average power deficits stratified by turbulence intensity for the wind direction sector $286^{\circ}-296^{\circ}$, which was the sector with the second highest power deficits. The features and trends in the power deficits are quite similar to those in Figure 3.16, which indicates that there is consistency in these results. Table 3.4 gives the number of 1 -min-averaged data samples in the wake and non-wake data sets used in calculating the average power deficits for each turbulence intensity category.

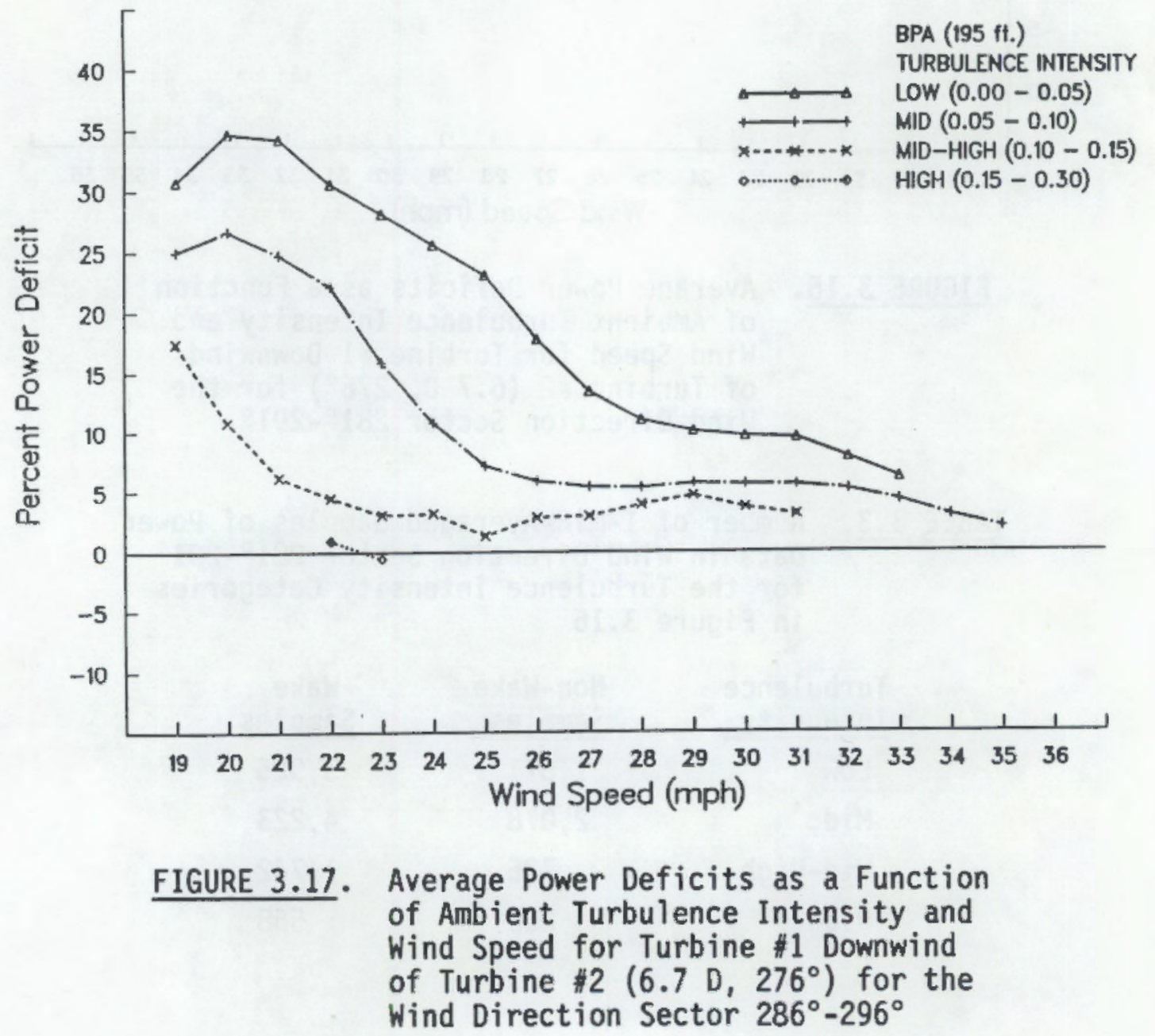


TABLE 3.4. Number of 1-min-Averaged Samples of Power Data in Wind Direction Sector $286^{\circ}-296^{\circ}$ for the Turbulence Intensity Categories in Figure 3.17

\begin{tabular}{|c|c|c|}
\hline $\begin{array}{l}\text { Turbulence } \\
\text { Intensity }\end{array}$ & $\begin{array}{l}\text { Non-Wake } \\
\text { Samples } \\
\end{array}$ & $\begin{array}{c}\text { Wake } \\
\text { Samples }\end{array}$ \\
\hline Low & 2,041 & 2,910 \\
\hline Mid & 2,787 & 3,204 \\
\hline Mid-High & 967 & 1,248 \\
\hline High & 370 & 448 \\
\hline
\end{tabular}

Figure 3.18 shows the wake power curves for Turbine \#1 (when it is in the wake of Turbine \#2), stratified by the ambient turbulence intensity, for the wind direction sector of $281^{\circ}-291^{\circ}$. The power output at $20 \mathrm{mph}$ for the high turbulence intensity is comparable to that at $26 \mathrm{mph}$ for low turbulence intensity. For wake conditions, it appears that the difference in power output

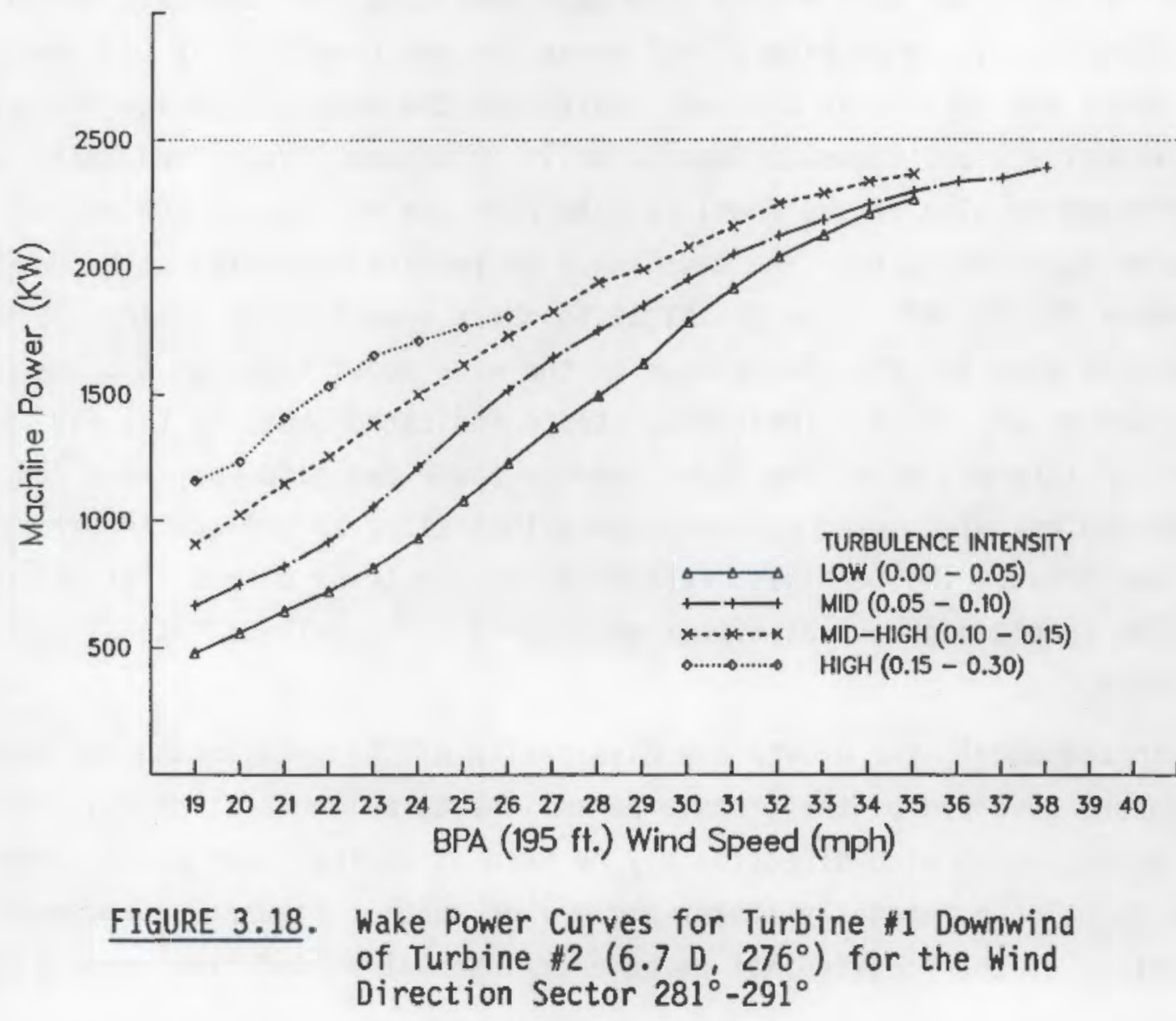


between the highest and lowest turbulence intensity categories is comparable to that of about a 5- to 6-mph difference in the mean wind speed. For nonwake conditions (see Figure 3.12), the difference in power output between the highest and lowest turbulence intensities was found to be comparable to that of a 3- to 4-mph difference in the mean wind speed. Thus, it is evident that the wake power curves are affected even more than the non-wake power curves by changes in the ambient turbulence intensity. This is because the wake effects are stronger at lower turbulence intensities, thus reducing the power significantly below that of the non-wake case; however, at higher turbulence intensities the wake effect diminishes, and the differences between the wake and non-wake power cases are relatively small.

\subsection{COMPARISON OF POWER DEFICITS TO WAKE MODEL ESTIMATES}

In this section, the average power deficits measured at $6.7 \mathrm{D}$ will be compared to estimates determined from a numerical wake model. Although a number of numerical wake models have been developed over the past decade, none have been given as wide attention as the one developed by Lissaman (1977). This model was revised in 1982 and tested for the machine configuration and meteorological conditions at Goodnoe Hills (Lissaman, Gyatt, and Zalay 1982). The revised version of the model is used here for the comparison against the measured power deficits. The baseline wind turbine characteristics used in the model for the MOD-2 are identical to those specified by Boeing (1979) and previously used for the simulations in the wake model tests at Goodnoe Hills (Lissaman et al. 1982). Those model tests indicated that, in the far wake region of interest here, the MOD-2 average power deficits vary as a function of the ambient wind speed and turbulence intensity, as well as the separation distance between the turbines. Essentially, the tests showed that the power deficits should decrease as either wind speed or turbulence intensity increases.

In the model, the growth and dissipation of the wake in the far-wake region are governed by the transverse ambient turbulence intensity. The standard deviation of wind direction may be used as an indicator of the transverse turbulence intensity (Baker and Walker 1985). Figure 3.19 presents a comparison of the longitudinal turbulence intensities and transverse turbulence 


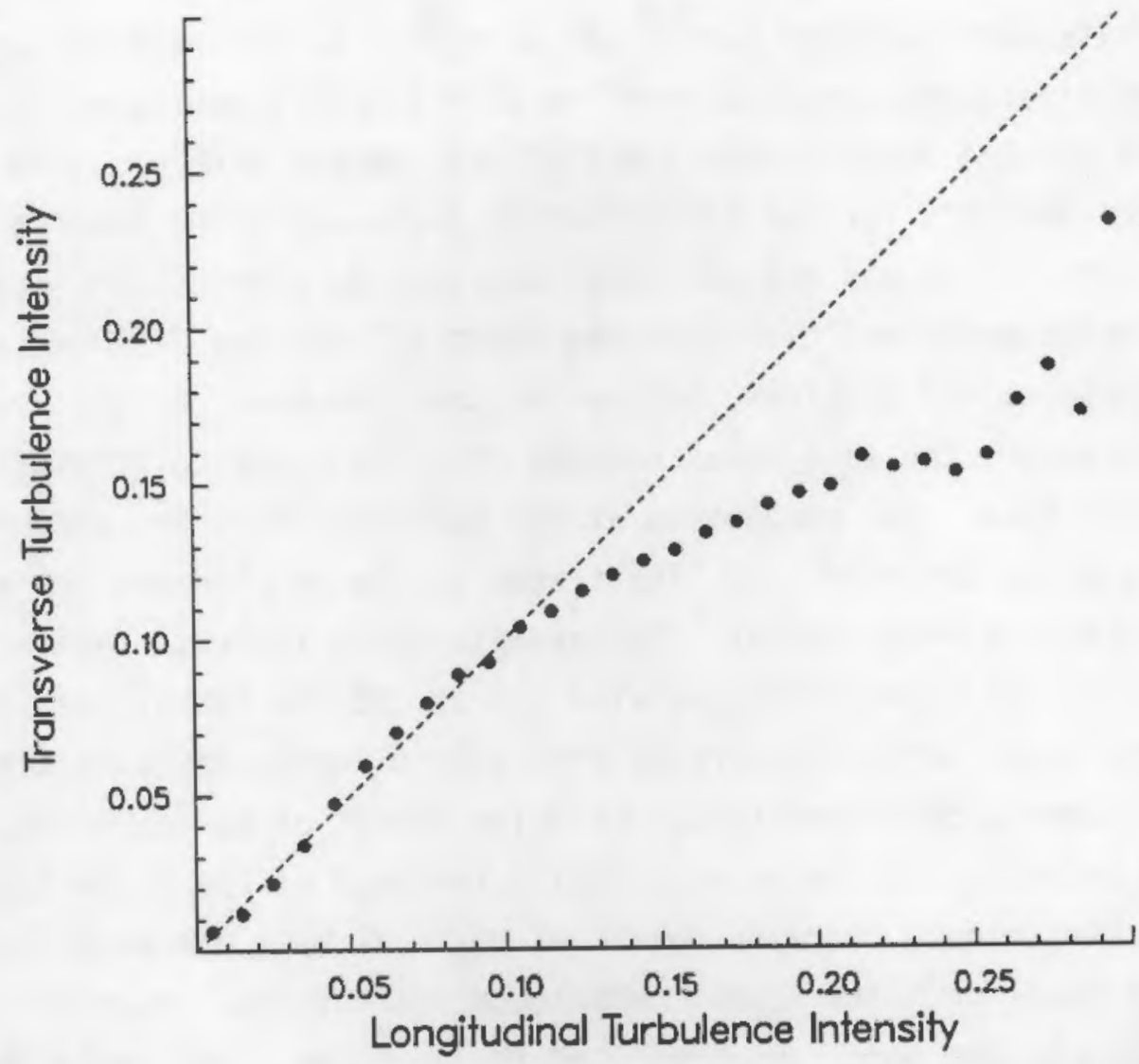

FIGURE 3.19. Comparison of the Longitudinal Turbulence Intensities and Transverse Turbulence Intensities at Goodnoe Hills, Based on 1985 Data from the 195-ft Level of the BPA Meteorological Tower for Wind Speeds $>13 \mathrm{mph}$ and Wind Directions Between $220^{\circ}$ and $320^{\circ}$

intensities at Goodnoe Hills, based on 1985 data from the 195- $\mathrm{ft}$ level of the BPA meteorological tower. For low, mid, and mid-high longitudinal turbulence intensities $(0.00$ to 0.15$)$, there is little difference between the longitudinal and transverse turbulence intensities and the two may be considered comparable. However, for longitudinal turbulence intensities greater than 0.15 , transverse turbulence intensities are significantly less than longitudinal turbulence intensities.

We executed the model to compute the average power deficits for the wake case of Turbine \#1 downwind of Turbine \#2 $\left(6.7 \mathrm{D}, 276^{\circ}\right)$. In the model runs, we used the following mid-point values for transverse turbulence intensity: $0.025,0.075,0.120$, and 0.150 , corresponding to the four categories--low, mid, mid-high, and high, respectively. Hub height wind speeds were specified. 
Power deficits were averaged over a $10^{\circ}$ direction sector centered about $276^{\circ}$ (i.e., wind directions were specified as $271^{\circ}$ to $281^{\circ}$ ) and speed intervals of $3 \mathrm{mph}$. The modeled deficits for the $271^{\circ}-281^{\circ}$ sector were compared against the measured deficits for the $10^{\circ}$ direction sector with the highest average power deficits. This was the $281^{\circ}-291^{\circ}$ sector. As previously discussed, the maximum average power deficits occurred about $10^{\circ}$ off the $276^{\circ}$ centerline direction between the turbines, indicating that the wake, on the average, is curving. However, the wake model assumes that the center of the wake travels in a straight line. The comparison of the modeled versus the measured power deficits is shown in Table 3.5. The trends in the modeled and the measured power deficits are very similar. For example, both indicate that average power deficits are highest for low wind speeds and low turbulence intensities and that the power deficits decrease with either increasing wind speeds or increasing turbulence intensities. For wind speeds of 19 to $24 \mathrm{mph}$, there is quite good agreement in the power deficits for each of the three turbulence intensity categories. For wind speeds of 25 to $27 \mathrm{mph}$, the model overpredicted the average power deficits at all turbulence intensities. However, for speeds of 28 to $30 \mathrm{mph}$, the model overpredicted the measured values only for low

TABLE 3.5. Percent Power Deficits for Turbine \#1 Downwind of Turbine \#2 $\left(6.7 \mathrm{D}, 276^{\circ}\right)$ Calculated from the Modified Lissaman Model Versus the Measured Results for Wind Directions $281^{\circ}-291^{\circ}$, as a Function of BPA 195-ft Wind Speed and Turbulence Intensity

\begin{tabular}{|c|c|c|c|c|c|}
\hline \multirow{2}{*}{$\begin{array}{l}\text { Turbulence } \\
\text { Intensity }\end{array}$} & \multicolumn{5}{|c|}{ Wind Speed (mph) } \\
\hline & $19-21$ & $22-24$ & $25-27$ & $28-30$ & $31-33$ \\
\hline \multicolumn{6}{|l|}{$0.00-0.05$} \\
\hline Modeled & 45 & 34 & 29 & 18 & 3 \\
\hline Measured & 43 & 37 & 20 & 11 & 9 \\
\hline \multicolumn{6}{|l|}{$0.05-0.10$} \\
\hline Modeled & 28 & 21 & 18 & 7 & 0 \\
\hline Measured & 30 & 24 & 9 & 9 & 7 \\
\hline \multicolumn{6}{|l|}{$0.10-0.15$} \\
\hline Modeled & 19 & 15 & 12 & 3 & 0 \\
\hline Measured & 22 & 12 & 8 & 6 & -- \\
\hline
\end{tabular}


turbulence intensity and slightly underpredicted the measured values for mid and mid-high turbulence intensities. At wind speeds of 31 to $33 \mathrm{mph}$, the model underpredicted the measured deficits. 



\subsection{CONCLUSIONS}

Meteorological and MOD-2 turbine data collected at the Goodnoe Hills site from April 1 to October 17, 1985, have been analyzed to evaluate wake characteristics and how they affect power output, and the influence of atmospheric factors. The influences of variations in the ambient wind speed, wind direction, and turbulence intensity were the primary factors evaluated.

An examination of the effect of wakes on the measured winds at the PNL tower has shown that

- the maximum velocity deficits are about $25 \%$ and $12 \%$ at downwind distances of $5.8 \mathrm{D}$ (Turbine\#2/PNL) and $8.3 \mathrm{D}$ (Turbine\#3/PNL), respectively.

- for the Turbine\#2/PNL wake case, the maximum velocity deficit occurs at a BPA wind direction of $306^{\circ}$. This is $14^{\circ}$ off the Turbine $2 /$ PNL centerline orientation of $292^{\circ}$, indicating that the wake may curve significantly between Turbine \#2 and the PNL tower. Wake curvature may also occur between Turbine \#3 and the PNL tower; however, it is not as pronounced as the curvature between Turbine \#2 and PNL tower.

- for the Turbine\#2/PNL wake case, the maximum velocity deficit depends somewhat on the free-stream wind speed. The deficit is largest, about $27 \%$, at the lower speeds ( 15 to $25 \mathrm{mph}$ ). As the speed increases to between 30 and $35 \mathrm{mph}$, the deficit decreases to about $20 \%$.

- the turbulence intensity increases dramatically in the wake. For the Turbine\#2/PNL and Turbine\#3/PNL wake cases, the turbulence intensity at the PNL tower increases by factors of about 2.3 and 1.5, respectively, over ambient conditions.

An analysis of the ambient (non-wake) power production for all three turbines at Goodnoe Hills showed that

- the MOD-2 power output depends, not only on wind speed, but also the turbulence intensity of the wind. 
- at wind speeds below rated, there was a dramatic difference in turbine power output between the highest and lowest turbulence intensity categories. This difference was comparable to that of about a 3-to 4-mph difference in the wind speed.

- Turbine $\# 3$, which had vortex generators on the blades, produced from $10 \%$ to $13 \%$ more power than the other two turbines when speeds were from 24 to $31 \mathrm{mph}$.

- the difference in power output between Turbine $\# 1$ and Turbine $\# 2$ was quite small $(<3 \%)$ except at very low wind speeds $(<18 \mathrm{mph})$. An analysis of the average power deficits for Turbine \#1 downwind of Turbine \#2 $\left(6.7 \mathrm{D}, 276^{\circ}\right)$ found that

- power deficits depend on the ambient wind speed. Power deficits are greatest at low wind speeds and decrease with increasing wind speed.

- for example, maximum average power deficits are $32 \%$ at $20 \mathrm{mph}, 17 \%$ at $25 \mathrm{mph}, 9 \%$ at $30 \mathrm{mph}$, and about $5 \%$ at $35 \mathrm{mph}$.

- maximum average power deficits occur at BPA wind directions of $286^{\circ}$ to $288^{\circ}$. This is $10^{\circ}$ to $12^{\circ}$ off the Turbine $\# 2 /$ Turbine $\# 1$ centerline orientation of $276^{\circ}$, indicating that the wake may curve significantly between Turbine \#2 and Turbine \#1. (This curvature was also evident in the analysis of the velocity deficits for Turbine \#2/PNL and Turbine \#3/PNL.)

- power deficits also depend on the ambient turbulence intensity. Largest deficits occur when the ambient turbulence intensity is low, and deficits decrease with increasing turbulence intensity. For low turbulence intensity, power deficits range from $43 \%$ at $20 \mathrm{mph}$ to $28 \%$ at $25 \mathrm{mph}$ and $10 \%$ at $30 \mathrm{mph}$.

Some of these results have generic importance for estimating power production and wake effects. Turbine power output was found to be highly dependent on not only wind speed but also the turbulence intensity of the wind. For MOD-2s and other types of turbines whose power production varies as a function of turbulence intensity, the importance of collecting turbulence intensity data, as well as time-averaged wind speed data, for use in estimating power 
production at a potential site cannot be overemphasized. However, a turbine's power output as a function of turbulence intensity, as well as wind speed, must be known in order to utilize these data in siting applications. Power deficits caused by turbine wakes were also found to vary as a function of wind speed and turbulence intensity. This relationship indicates that wake effects are very site dependent, because average power deficits may be quite different at sites that do not have similar frequency distributions of wind speed and turbulence intensity. Other important factors that should be considered in estimating power output and wake effects are the terrain complexity and vertical profiles of wind speed, wind direction, and turbulence intensity. Large errors in predictions of power output and/or wake effects could result if a site's wind profile characteristics were significantly different from those of the basic site(s) used in establishing the power curves and wake effects. 


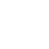




\subsection{REFERENCES}

Baker, R. W., and S. N. Walker. 1982. Wake Studies at the Goodnoe Hills MOD-2 Site. Report No. 82-11, BonneviTle Power Administration, Portland, oregon.

Baker, R. W., and S. N. Walker 1985. Wake Velocity Deficit Measurements at the Goodnoe Hills MOD-2 Site: A Summary of the 1982 and 1984 Findings. Report No. 84-15, Bonneville Power Administration, Portland, Oregon.

Buck, J. W., and D. S. Renne 1985, Observations of Wake Characteristics at the Goodnoe Hills MOD-2 Array. PNL-5565, Pacific Northwest Laboratory, Richland, Washington.

Germain, A. C. 1984. Effects of Selected Atmospheric Variables on the Power Output of a DOE MOD-2 Wind Turbine. Master's Thesis, Oregon State University, Corvallis, Oregon.

HadTey, D. L., and D. S. Renne. 1983. "Wake Research in the Federal Wind Energy Program." In Proceedings of ASES '83 Annual Meeting and Wind Workshop VI, June 1983, American Solar Energy Society, Boulder, Colorado.

Lissaman, P. B. S., G. W. Gyatt and A. D. Zalay. 1982. Numeric Modeling Sensitivity Analys is of the Performance of Wind Turbine Arrays. PNL-4183, Pacific Northwest Laboratory, Richland, Washington.

Lissaman, P. B. S., T. G. Zambrano and G. W. Gyatt. 1983. Wake Structure Measurements at the MOD-2 Cluster Test Facility at Goodnoe Hills. PNL-4572, Pacific Northwest Laboratory, Richland, Washington.

Liu, H.-T., J. W. Waite, T. R. Heister, P. H. Tacheron and R. A. Srnsky. 1983. Flow Visualization Study of the MOD-2 Wind Turbine Wake. PNL-4535, Pacific Northwest Laboratory, Richland, Washington.

Miller, A. H., H. L. Wegley and J. W. Buck. 1984. "Large HAWT Wake Measurement and Analysis." Paper presented at the DOE/NASA Wind Turbine Technology Workshop, May 8-10, 1984, Cleveland, Ohio.

Miller, G. E. 1985. Wake Interference Effects On MOD-2 Power Performance and Rotor Loads. Boeing Document D277-1034-1, Boeing Aircraft Corporation, Kent, Washington.

Sullivan, T. L. 1984. Effect of Vortex Generators on the Power Conversion Performance and Structural Dynamic Loads of the MOD-2 Wind Turbine. NASA TM-83680, NASA Lewis Research Center, Cleveland, ohio. 


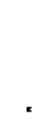


APPENDIX A

DESCRIPTION OF THE DISTRIBUTED DATA SYSTEM (DDS) 
APPENDIX A

\section{DESCRIPTION OF THE DISTRIBUTED DATA SYSTEM (DDS)}

A centralized data logging system, known as the Distributed Data System (DDS), was installed at the site to monitor data collected from both the meteorological towers and the three MOD-2 turbines. The DDS consisted of a microcomputer hard-surface disk drive, a terminal, and a tape drive for backup storage and system loading. The disk was used as stored system programs and data collected from the towers and turbines. This system was upgraded in 1984 with a new operating system that allowed plotting of current or stored data using the new graphics terminal or a hard copy plotter. Other new software allowed for easier definition of channels and data records. These modifications permitted researchers to easily change data records to conform to specific tests and to plot the data during and after collection.

The DDS was designed to collect and record data on a conmon time basis from up to 32 channels from eight different locations around the site. All signals are transmitted through underground fiber optic cables from the three turbines and two towers to a central data trailer. The fiber optic cables were then connected to the DDS for processing and storage. Figure A.1 shows a schematic of the various components of the DDS in 1985 at Goodnoe Hitls.

The time reference was controlled by a battery-operated clock that would not lose time even if there was an electrical power failure. If power to the data trailer was shut off, the DDS would close the current data file to prevent data loss. When the power was off, no data were collected. Once the power was back on, the DDS would automatically restart the computer and give it the current time from the battery-operated clock. The DDS would then begin a new data file with the current time stamp.

The software provided with the DDS gives the user the following data collection options:

- selection of data channels to be contained by the data file

- selection of data sampling interval 


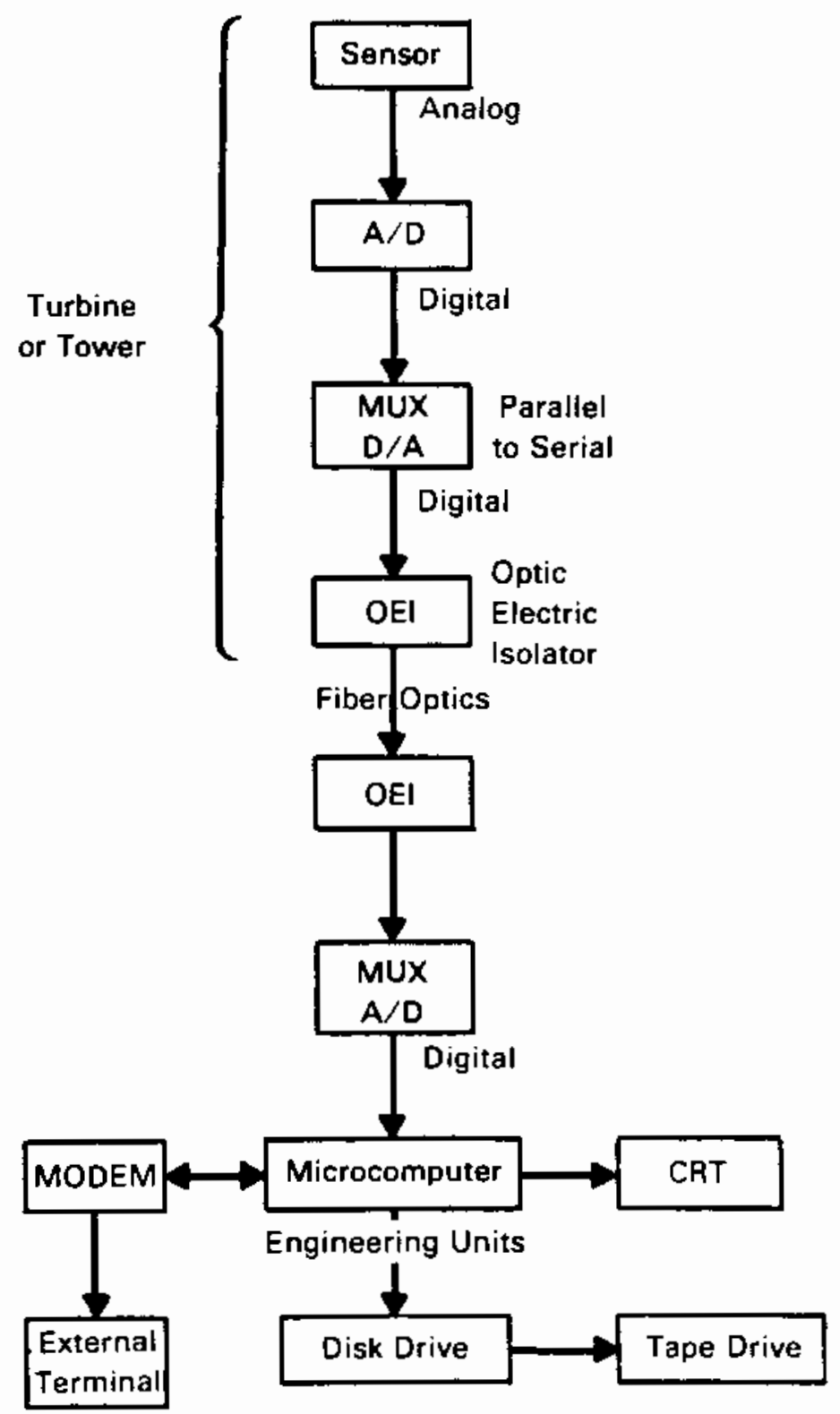

FIGURE A.1. Schematic of the Information Flow Through the Distributed Data System (DDS) at the Goodnoe Hills Site

- selection of data sampling format (averaged with standard deviations or instantaneous values)

- selection of the time period of the data file.

Once these options were decided, the system could be programmed to collect exactly the data the user wants. In normal operations, the DDS at the Goodnoe Hills Site collected 45 channels of data: 15 channels from the PNL tower,

\section{A.2}


6 channels from the BPA tower, and 8 channels from each of the turbines. The sample rate was one per second and the data were averaged every 1 minute. A standard deviation was also computed for every parameter collected. The time period for the data files was 1 day.

Other software in the computer provided monitoring functions, such as which data files were active and which channels were being collected in the file. Other monitoring functions, such as the number of data files were already created, and the amount of free space available on the disk, were also on the system. Software for plotting current or stored data allowed the user to check the data and confirm it was there. Hard copies of the plots were also an option. An example of a plot that was made in the field is given in Figure A.2. This figure gives Turbine $\# 1$ and \#2 power (multiply the y-scale by 1000 to get $\mathrm{kW}$ ), the BPA $195-\mathrm{ft}$ wind speed (multiply the y-scale by 100 to

CDS 13

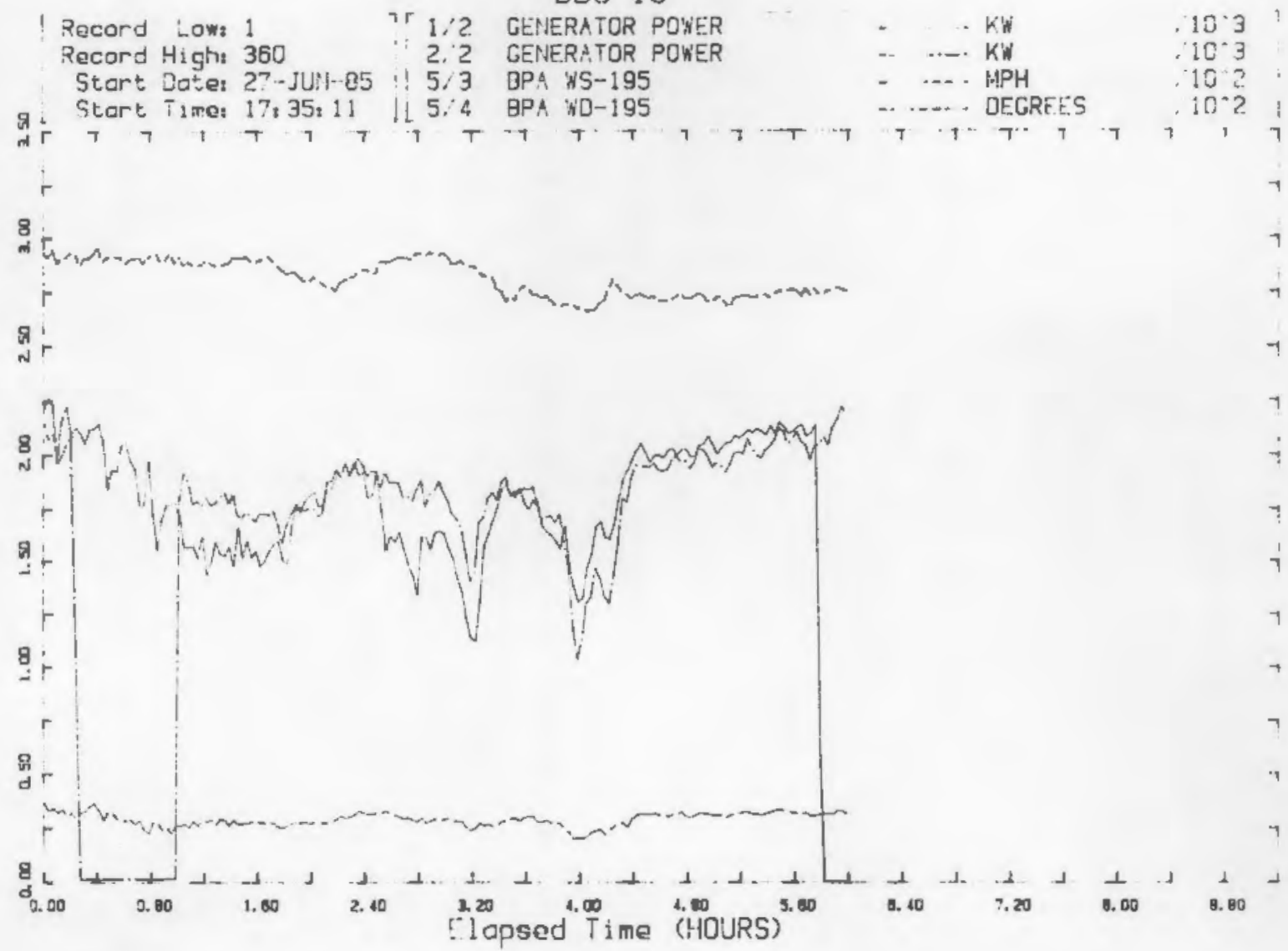

FIGURE A.2. An Example of a Plot Made in the Field to Check the Turbine and Tower Data 
get mph), and BPA wind direction (multiply y-scale by 100 to get degrees). This particular plot is of 1-second data and indicates a wake from Turbine \#2 on Turbine \#1. This software improved the reliability of the data being collected. 
APPENDIX B

DATA PROCESSING 
APPENDIX B

\section{DATA PROCESSING}

This appendix describes the calculations that produce speed ratios and turbulence intensity ratios as functions of wind direction. The non-wake and wake data sets, as described in Section 3.1, consist of 1-min averages of wind speeds, speed standard deviations, and wind directions for both the BPA and PNL towers. The determination of speed and turbulence intensity ratios is necessarily an averaging process where for a given wind direction, a subset of these data sets is selected, processed, and averaged to produce the desired ratios.

The first step of this analysis examines the correlation between the BPA and PNL wind directions; this correlation is portrayed in Figure B.1. In this figure, for each 1-min average, PNL wind direction is plotted versus BPA wind direction. For clarity's sake, only every 20th point is plotted for the non-wake set (out of a possible 6,015 points), and only every 100th point is plotted for the wake set (out of a possible 30,409 points). Physically, one would expect a high degree of correlation between wind directions, and indeed, this is clearly apparent in Figure B.1. The relationship between the BPA and PNL directions seems quite linear over the range of wind directions considered here, and therefore we can assume that a linear model closely approximates the relationship between these quantities.

Next, lines of regression are fit to the wind direction data. The standard linear regression model is not appropriate in this situation because it assumes that the independent variable, $x$, is known without error, and that the departure from linearity occurs solely because of random fluctuations in the dependent variable, $y$. For the case at hand fluctuations in $x$ also occur, and the regression model must condsider this. One way of calculating a line of regression when $x_{1}$ as well as $y$, have a random component is so-called "perpendicular regression," where the sum of the squares of the perpendicular distances from the regression line to the points is minimized. [Perpendicular regression is equivalent to "principal components regression" described in 

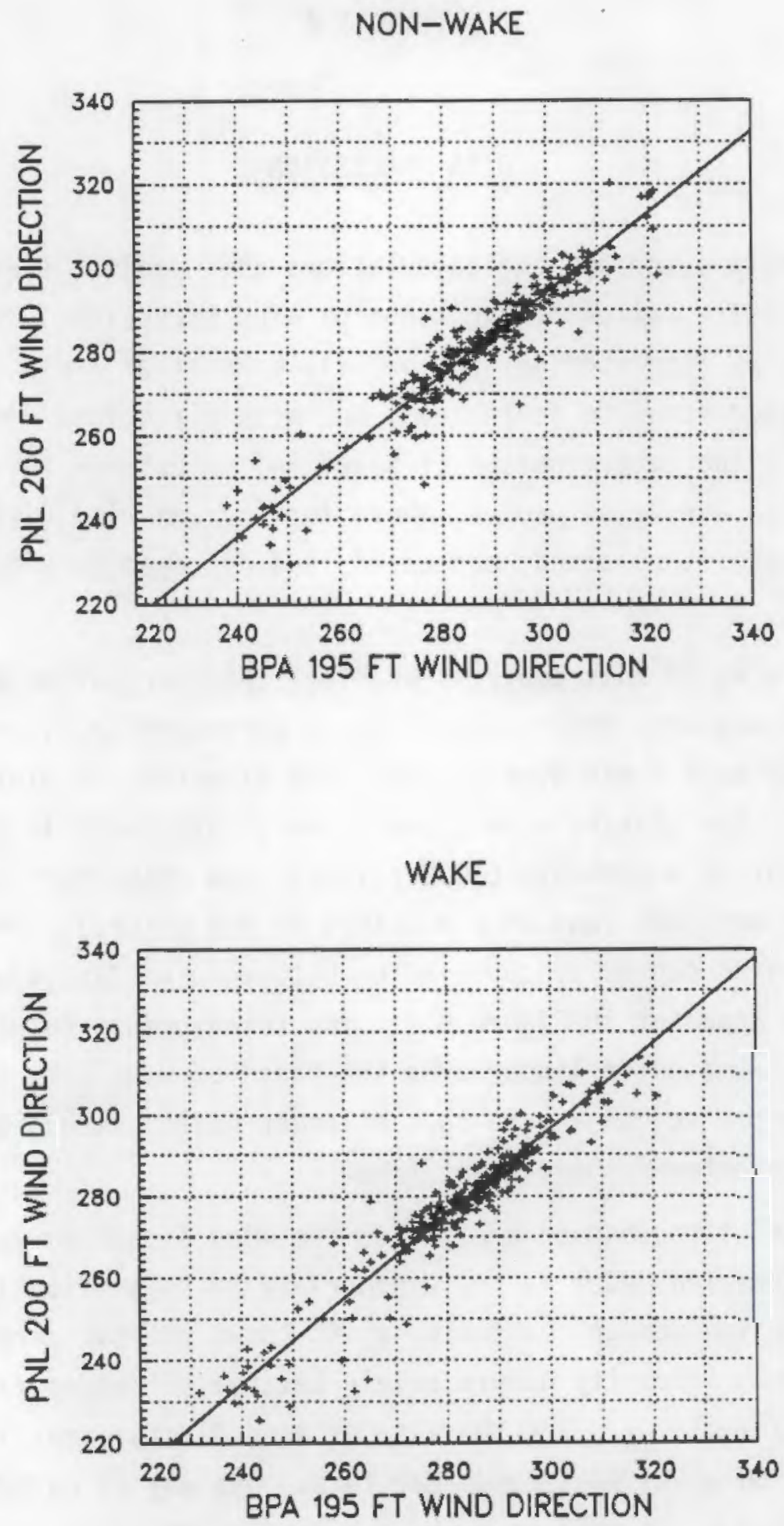

FIGURE B.1. PNL Wind Direction Plotted Versus BPA Wind Direction for Both the Non-Wake and Wake Data Sets. The solid lines are lines of perpendicular regression fit to these data.

\section{B.2}


Draper and Smith (1981).] Using this technique, the regression equation is the same regardless if $x$ or $y$ is used as the independent variable. Lines of perpendicular regression are also shown in Figure B.1, and these are for the non-wake case, (PNL direction) $=0.965$ (BPA direction) +4.44 ; and for the wake case, (PNL direction) $=1.037$ (BPA direction) -14.62 . We assume that these regression lines correctly describe the relationship between the averages of PNL and BPA directions, and that actual departures from the line are caused either by random measurement errors or random wind field fluctuations.

The regression lines provide a means for selecting data that can be averaged to provide wind speed ratios, turbulence intensity ratios, or other quantities of interest. Say that we wish to calculate the non-wake wind speed ratios at $1^{\circ}$ increments of BPA wind direction. Given the BPA direction, we find the corresponding PNL direction from the non-wake regression line. These two directions form the center of a region from which data may be chosen for averaging. This region is taken to be a circle because a circle does not preferentially weight either the BPA or PNL direction. Each wind direction pair within the circle corresponds to a pair of BPA and PNL wind speeds, observed during the same minute as the directions. Thus for each point in the circle, a wind speed ratio can be formed, and all these can be averaged to compute an average non-wake ratio for the specified direction. The averaging that is performed is actually a weighted average that weighs data at the center of the circle more than at the edge. This is accomplished by a Gaussian weighing function $w(r)$ :

$$
w(r)=\frac{1}{\sqrt{2 \pi} \sigma} e^{-\frac{r^{2}}{2 \sigma^{2}}}
$$

where $r$ is the distance from the center of the circle to the point in question, and $\sigma$ is a measure of the width of the weighing function. The radius of the circle is chosen to be $3 \sigma$; at this distance the weighing function is virtually zero.

The averaging process is illustrated in Figure B.2. Here we have specified a BPA direction of $306^{\circ}$, and accordingly, the origin of the circle is positioned at coordinates $B P A=306^{\circ}$ and $P N L=299.8^{\circ}$. (The PNL direction is 


\section{NON-WAKE}

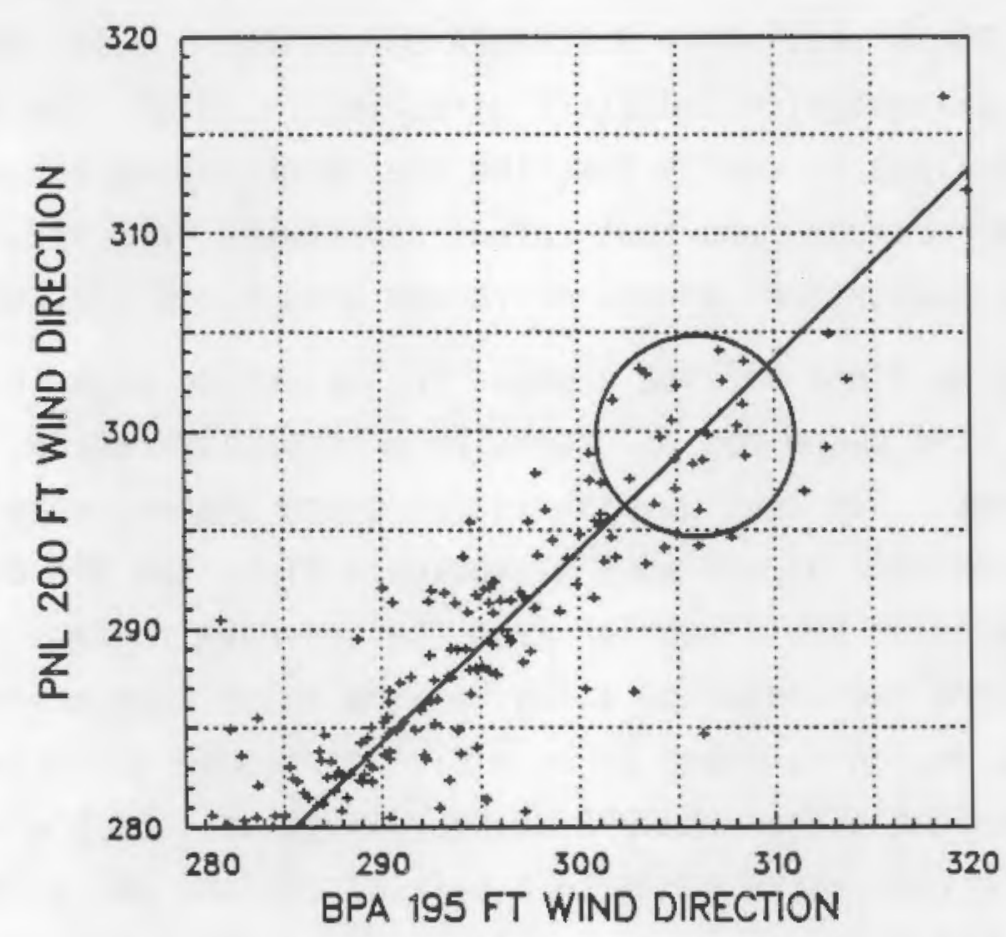

FIGURE B.2. Circle Over which Data is Averaged. For a BPA direction of $306^{\circ}$, the data indicated by the crosses within the circle are averaged to compute non-wake wind speed ratios, or other quantities of interest.

calculated through the non-wake regression line.) $\sigma$ is taken to be $1.69^{\circ}$, which results in a Gaussian function with a full-width at half-maximum of $4^{\circ}$. The circle's radius is $5.07^{\circ}$. The crosses within this circle comprise the subset of non-wake data that is averaged to determine the non-wake speed ratio at a BPA direction of $306^{\circ}$. (As in Figure B.1, only every 20th point is plotted in Figure B.2.) This averaging procedure is performed at integer BPA wind directions for both the wake and non-wake data to produce figure 3.4. If in this procedure, turbulence intensity ratios are substituted for wind speed ratios, then figure 3.6 results. 
The character of the functional relationship between the ratio and the wind direction will, of course, depend upon the width, $\sigma$, of the weighing function. In fact, because larger values of $\sigma$ result in averaging over more data, $\sigma$ acts as a smoothing paraneter. The amount of smoothing must be chosen with care: considerable smoothing may remove noise and make the shape of the ratio-versus-direction function clear; however, this comes at the expense of smoothing out the local extremes (i.e., peaks and valleys) of the function. Since we are interested in characterizing the maximum velocity deficit, a local minimum on the wake ratio-versus-direction curve, it is not desirable to use a large amount of smoothing. In practice, the amount of smoothing was chosen by experimenting with different values of $\sigma$, and finally a value of 1.69 was selected. With this value, the local extremes are only altered a very small amount.

\section{REFERENCE}

Draper, N. R., and H. Smith. 1981. Applied Regression Analysis. John wiley \& Sons, New York, New York. 



\section{DISTRIBUTION}

No. of

Copies

\section{OFFSITE}

C. I. Aspliden

Battelle Memorial Institute

Washington office

2030 M Street, NW

Washington, DC 20036

J. Cadogan

U.S. Department of Energy

Wind/Ocean Technologies Division

1000 Independence Avenue

Forrestal Building, Room $5 \mathrm{H} 048$

Washington, DC 20585

G. P. Tennyson

U.S. Department of Energy

Albuquerque Operations office

P.0. Box 5400

Albuquerque, NM 87110

10 DOE Office of Scientific and Technical Information

R. Baker

U.S. Windpower

6952 Preston Avenue

Livermore, CA 94550

W. Bollmeier

Solar Energy Research Institute

1617 Cole Boulevard

Golden, C0 80401

K. Cohn

Second Wind

880 Lombard Street

San Francisco, CA 94133

K. Cousineau

Zond Systems Incorporated

13000 Jameson Road

Tehachapi, CA 93561
No. of

Copies

E. Davis

U.S. Windpower

6952 Preston Avenue

Livermore, CA 94550

J. M. Fuchs

Fayette Manufacturing Corp.

P.0. Box 1149

Tracy, CA 95376

R. H. Holeman

Bonneville Power Administration P.0. Box 3621

Portland, OR 97208

N. Kelley

Solar Energy Research Institute 1617 Cole Boulevard

Golden, CO 80401

P. B. S. Lissaman

Aerovironment, Inc.

825 Myrtle Avenue

Monrovia, CA 91016-3424

P. Liu

Flow Industries, Inc.

21414 68th Avenue, $S$.

Kent, WA 98032

R. Lynette

R. Lynette and Associates, Inc. 15032 N.E. 40th Street, Suite 206 Redmond, WA 98052

R. Nierenberg

Howden Wind Parks, Inc. 1330 Lincoln Avenue, Suite 310

San Rafael, CA 94901

D. Reda

Sandia National Laboratories

Division 6225

Albuquerque, NM 87185 
No. of

Copies

R. Simon

434 Oakdale Avenue

Corte Madera, CA 94925

B. S. Smith

Grant Line Energy Corp.

15850 Jess Ranch Road

Route 5, Box 706

Tracy, CA 95376

D. A. Spera

NASA/Lewis Research Center 21000 Brookpark Rd.

Cleveland, $\mathrm{OH} 44135$

W. Thompson

Fayette Manufacturing Corp. P.0. Box 1149

Tracy, CA 95376

S. Veenhuizen

United Industries Corp.

12835 Bel-Red Road

Bellevue, WA 98005

J. Wade

Pacific Wind Energy

P.0. Box 1671

Corvallis, OR 97339
No. of

Copies

S. N. Walker

Pacjfic Wind Energy

P.0. Box 1671

Corvallis, OR 97339

ONSITE

DOE Richland Operations office

J. J. Sutey/D. R. Segna

22 Pacific Northwest Laboratory

J. C. Barnard

J. W. Buck

J. R. Connell

D. W. Dragnich

C. E. Elderkin

D. L. Elliott

M. J. Graham

J. M. Hales

P. C. Hays

V. R. Morris

E. L. Owczarski

D. C. Powell

J. A. Stott lemyre

L. L. Wende 11

R. E. Wildung

Publishing Coordination (2)

Technical Report Files (5) 